\title{
SOLUTRENSES DEL SUR DE IBERIA EN TRANSICIÓN
}

\author{
South Iberia Solutreans in transition
}

\author{
J. Emili Aura Tortosa ${ }^{1}$ y Jesús F. Jordá Pardo ${ }^{2}$
}

Recibido el 22 de septiembre de 2013. Aceptado el 17 de octubre de 2013

Resumen. La cuestión de las relaciones tecnoeconómicas entre el Solutrense y los complejos que lo enmarcan (Gravetiense y Badeguliense) permanence abierta y condicionada por los procesos erosivos que coinciden con estos momentos en la mayoría de yacimientos de la región mediterránea ibérica. El análisis de las industrias líticas de Parpalló y Nerja, así como el conjunto de las dataciones radiocarbónicas permite una aproximación a estas relaciones y una evaluación crítica de su marco cronológico.

Palabras clave: Solutrense, Gravetiense, Badeguliense, evolución tecnoeconómica, cronología radiocarbónica, sur de lberia.

\begin{abstract}
The relationship between the Solutrean and the Gravettian and Badegoulian is still an open issue, and the analysis of this relationship in most sites appears to be conditioned by the effects of erosive processes and taphonomy in sites of Iberian Mediterranean region. Analysis of the lithic industries from Nerja and Parpalló and the regional radiocarbon dates allows for a first evaluation of the technoeconomic relations between these tecnocomplexes and their chronological framework.
\end{abstract}

Keywords: Solutrean, Gravettian, Badegoulian, technoeconomical evolution, radiocarbon chronology, South of Iberia.

\section{INTRODUCCIÓN}

El Solutrense se desarrolló durante uno de los episodios más rigurosos del Pleistoceno superior, entre el final del evento de Heinrich 2 (HE2) y el último máximo glacial (LGM). Fue un tecnocomplejo breve, pero la gran visibilidad de sus proyectiles de piedra y su posición central lo han convertido en un punto de inflexión en la evolución del Paleolítico superior (Jordá 1955a; Smith 1966; Fullola Pericot 1979; Rasilla 1994; Straus 1990; Zilhão 1997; Tiffagom 2006a). Su variabilidad regional ha sido interpretada en términos paleoetnológicos, relacionando las geografías solutrenses con dinámicas que entrelazan cambios ecológicos, ciclos demográficos y redes territoriales (Straus et al. 2000;
Aubry et al., 2004; Gamble et al. 2004; Tiffagom et al. 2007; Banks et al. 2009; Schmidt et al. 2012).

En la región mediterránea ibérica, la construcción de la secuencia solutrense ha recorrido tres etapas. El interés por los cambios en las puntas de piedra guió la primera (Pericot 1942; Jordá 1955a) y la secuencia quedó fijada: puntas de cara plana / foliáceos bifaciales con retoque plano (hojas de laurel, piezas asimétricas, etc.) / puntas de aletas y pedúnculo / puntas de escotadura de retoque abrupto. En línea con los planteamientos del momento, la discusión sobre sus orígenes trazó dos direcciones básicas, el $\mathrm{N}$ de África y Francia.

Los primeros estudios paleoeconómicos (Davidson 1976) y la obtención de dataciones radiocarbónicas (Davidson 1974;

(') Dept. de Prehistòria i Arqueología. Facultat de Geografia i Història. Universitat de València. Avda. Blasco Ibáñez 28, E-46010 Valencia (España). jeaura@uv.es

(2) Dpto. de Prehistoria y Arqueología, Facultad de Geografia e Historia, Universidad Nacional de Educación a Distancia. Paseo Senda del Rey, 7. E-28040 Madrid (España). jjorda@geo.uned.es 
Fortea y Jordá 1976) coincidieron con la revisión de las industrias líticas de Parpalló y de su contexto regional (Fullola Pericot 1979). A partir de sus resultados se planteó la existencia de un sistema de asentamiento paleolítico con referencias mediterráneas y se fundamentó la existencia de un foco antiguo para el Solutrense ibérico, proponiendo una secuencia ordenada en tres bloques: Solutrense inicial, pleno y evolucionado, considerando parte del Solutrense evolucionado como equivalente al Solutreogravetiense (Fortea y Jordá 1976). La solidez de esta trayectoria regional dentro del suroeste de Europa quedó reforzada con los datos de Cueva Ambrosio, situando más al sur otro importante foco solutrense (Ripoll Perelló 1960-61; Ripoll López 1988; Ripoll López y Cacho 1990).

El tercer ciclo enlazó los cambios en la cultura material con el reconocimiento de una identidad regional. La reivindicación de un "arte solutrense", no limitado a las plaquetas de Parpalló, fue argumentado por Jordá (1955b). Este rasgo fue configurándose como un importante elemento regional que vino a reforzar la antigüedad del proceso de solutreanización, su dinamismo y singularidad (Fortea Pérez 1978; Villaverde y Fullola 1990; Villaverde 1994); aunque, finalmente, las relaciones del primer arte solutrense se orientaron hacia sustratos gravetienses (Fortea 2005).

Por tanto, seriación arqueológica, cronología radiocarbónica y relaciones regionales han sido tres cuestiones centrales. En los últimos años se han dado a conocer nuevos yacimientos y dataciones en la región mediterránea (cf. Mangado 2010) que permiten retomar dos temas que estuvieron muy presentes en el congreso celebrado en Los Vélez (Almería). La primera se refiere a las relaciones tecnoeconómicas del Solutrense con los complejos que se sitúan en sus límites. La segunda es el modelo cronológico que deriva de los datos radiocarbónicos.

\section{EN LOS LIIMITES DEL SOLUTRENSE IBÉRICO}

La mayoria de secuencias litoestratigráficas muestran hiatos y procesos erosivos que causan vacios documentales coincidiendo con los límites del Solutrense. Estas dinámicas suelen limitar la comprensión de las relaciones con el Gravetiense final y con el Badeguliense/Magdaleniense (Aura et al. 2006).

La confrontación de las producciones líticas del Solutrense inicial y del Gravetiense plantea dificultades por la escasez de conjuntos (Villaverde et al. 2008; de la Peña 2011). El interés por esta dinámica evolutiva quedó patente a partir del análisis de la secuencia de Nerja, uno de los yacimientos más meridionales del Solutrense occidental y situado sobre la llanura costera, el gran vial de conexión entre las redes de los grupos paleolíticos.

En su límite más reciente existen procesos sedimentarios que están afectando a su definición y desarrollo tem- poral, en relación con el Badeguliense y el Magdaleniense inferior clásico (Aura 2007; Aura et al. 2012; Utrilla y Montes 2007; Utrilla et al. 2012; Villaverde et al. 2012).

\subsection{Cueva de Nerja: del polimorfismo gravetiense a los inicios del Solutrense}

Las ocupaciones gravetienses de Nerja (NV13 - NV11) están datadas entre 29940 y 28580 años cal BP. Tras un hiato erosivo, los niveles NV10, NV9 y NV8 fueron considerados solutrenses quedando datados entre 25570 cal BP (NV 9) y 18810 cal BP (NV 8/s) (Jordá y Aura 2008; Aura et al. 2010a). El primer análisis de sus industrias líticas y óseas permitió una valoración sobre los inicios del Solutrense en el sur de Iberia (Aura et al. 2006) y durante 2007 realizamos una primera comparación con los datos de Parpalló cuyos resultados fueron presentados en la reunión de Preuilly-surClaise (Tiffagom et al. 2007). Los materiales gravetienses han sido publicados recientemente, insistiendo en este planteamiento (Aura et al. 2010b; 2013).

Las industrias líticas talladas de estos niveles suman cerca de 4900 restos. El 98\% del conjunto está fabricado sobre sílex, mientras que cristal de roca y cuarzo suponen en torno al 1,5\% y la cuarcita el resto. Menos del 10\% del utillaje retocado gravetiense y solutrense muestra restos de córtex, sólo el $2 \%$ puede considerarse fabricado sobre soportes corticales y un $23 \%$ presenta algún grado de alteración térmica. Las fases de consumo y abandono concentran la gran mayoría de los materiales en el tramo basal de la secuencia (NV13 - NV11), mientras que la fabricación/reparación se hace cada vez más patente a partir de NV10.

Dejando de lado los restos de talla y los irrelevantes (fragmentos de informes, corticales y restos alterados), en este trabajo se han utilizado algo más de 1300 restos que han permitido reconocer 4 producciones básicas: la talla laminar y la microlaminar, el facetado solutrense y la talla de lascas (Fig. 1).

Se ha podido identificar una talla de láminas estrechas que, por su relación con soportes retocados, parece vinculada a la fabricación de proyectiles y también buriles, algunos sobre truncadura de sección trapezoidal gruesa. Estos soportes se han obtenido a partir de núcleos prismáticos de frente estrecho y dirección unipolar y bipolar.

La producción de láminas anchas también está documentada, algunas con bordes convergentes. Los restos de núcleos permiten reconocer núcleos prismáticos, planos con series unipolares de explotación de su cara más ancha. Junto a estas piezas planas se han reconocido soportes apuntados, lascas laminares, robustas en ocasiones, obtenidas con percutor duro y cercanas al Levallois, cuya preparación convergente es la que deriva en su apuntamiento. Esta producción, documentada básicamente por los soportes, ha sido denominada "estilo Vale Comprido", puesto que no reconocemos 


\begin{tabular}{|c|c|c|c|c|c|c|}
\hline & \multicolumn{3}{|c|}{ Talla laminar - Talla microlaminar } & & \multicolumn{2}{|c|}{ Talla de lascas } \\
\hline & Láminas & $\begin{array}{l}\text { Lam. anchas } \\
\text { (\% sobre I lam) }\end{array}$ & $\begin{array}{l}\text { Micro } \\
\text { láminas }\end{array}$ & $\begin{array}{l}\text { Núcleos Núcleos } \\
\text { raspador } \mathrm{B}+\mathrm{GB}\end{array}$ & Lascas & $\begin{array}{l}\text { Facetado } \\
\text { solutrense }\end{array}$ \\
\hline NV $8 / \mathrm{s}$ & & & & & & \\
\hline NV 8 & & & & & & \\
\hline NV $8^{\prime}$ & & & & & & \\
\hline NV 9 & & & & & & \\
\hline NV10 & & & & & & \\
\hline NV11 & & & & & & \\
\hline NV13 & & & & & & \\
\hline
\end{tabular}

\begin{tabular}{|c|c|c|c|c|c|c|}
\hline & NV13 -11 & NV 10 & NV 9 & NV $8^{\prime}$ & NV 8 & NV/8s \\
\hline T. laminar & 69,2 & 67 & 55,3 & 39,7 & 30,2 & 22,3 \\
\hline T. microlaminar & 11,5 & 9,8 & 11,4 & 16,1 & 22,5 & 29,2 \\
\hline T. núcleos-raspador & 0,6 & 2,9 & 1,6 & 3,2 & 2 & 3,2 \\
\hline T. núcleos-buril y GB & 9,6 & 7,4 & 5,9 & 7 & 7,4 & 5,3 \\
\hline T. de Lascas & 4,8 & 17,1 & 9,4 & 23,1 & 19,9 & 28,2 \\
\hline Facetado solutrense & 4,3 & 5,7 & 16,5 & 10,9 & 17,9 & 11,7 \\
\hline Totales & 208 & 244 & 255 & 156 & 251 & 188 \\
\hline - Láminas anchas (\% respecto T, lam) & 11,1 & 10,8 & 28 & 18,5 & 14,5 & 4,5 \\
\hline Raspadores sobre lámina & 5 & 5 & 6 & 10 & 4 & 1 \\
\hline Raspadores sobre lasca & 3 & 3 & 3 & 3 & 13 & 15 \\
\hline Buriles diedros & 2 & 4 & 3 & 7 & 7 & 4 \\
\hline Buriles sobre $\mathrm{T}$ y retoque & 4 & 3 & 2 & 3 & 2 & 1 \\
\hline Truncaduras & 7 & 2 & 0 & 3 & 4 & 3 \\
\hline Grupo solutrense & 0 & 1 & 5 & 4 & 9 & 6 \\
\hline P. esquirladas & 5 & 3 & 3 & 4 & 5 & 1 \\
\hline Utillaje microlaminar & 6 & 0 & 1 & 2 & 6 & 10 \\
\hline P. de escotadura & 0 & 0 & 0 & 0 & 1 & 1 \\
\hline Puntas de aletas y pedúnculo & 0 & 0 & 0 & 0 & 0 & 0 \\
\hline Foliáceos (+ frags. reutilizados) & 0 & 0 & 3 & 2 & 5 & 2 \\
\hline Hojas de laurel & 0 & 0 & 0 & 1 & 0 & 0 \\
\hline Puntas de cara plana & 0 & 1 & 2 & 1 & 3 & 3 \\
\hline Soportes estilo Vale Comprido & 1 & 1 & 3 & 0 & 1 & 0 \\
\hline Utillaje microlaminar retoque $\mathrm{A}$ & 4 & 0 & 0 & 1 & 4 & 8 \\
\hline Utillaje microlaminar retoque $\mathrm{S}$ & 2 & 0 & 1 & 1 & 2 & 2 \\
\hline $\mathrm{N}^{2}$ total de útiles retocados & 98 & 74 & 76 & 86 & 128 & 91 \\
\hline
\end{tabular}

A Figura 1. Cueva de Nerja, sala del Vestíbulo. En la parte superior, frecuencia de las producciones líticas descritas en el texto (suma de soportes, piezas de acondicionamiento y núcleos); la frecuencia de láminas anchas está referida al conjunto de la talla laminar. En la parte inferior y de arriba abajo: valores de las producciones líticas, desglose de los principales grupos de útiles retocados $\mathrm{y}$ de las puntas gravetienses y solutrenses. 
extracciones proximales de la cara superior tan pautadas como en los morfotipos portugueses (Zilhão y Aubry 1995). Su presencia en los niveles basales establece un elemento de continuidad entre NV12 y NV9.

La producción microlaminar queda prácticamente integrada en la laminar durante el Gravetiense, obteniéndose a partir de núcleos de frente estrecho al menos hasta NV 10. La obtención de microlaminitas y esquirlas a partir de núcleos-raspador se concentra entre NV10 y NV8', incluyendo un raspador nucleiforme sobre cristal de roca; la gran mayoría de estos soportes microlaminares no ofrecen retoque (Zilhão et al. 1999). La presencia de buriles-núcleos se registra también en los niveles basales (NV13 a NV9) y de hecho el único proyectil gravetiense de dorso completo está elaborado sobre un soporte de estas características. En los tramos NV8 y NV8/s la talla microlaminar se realizó sobre núcleos prismáticos y piramidales y en el tramo superior se aprecia un repunte de los núcleos-raspadores, en el contacto con el Magdaleniense (Figs. 1 y 2).

Las lascas muestran un incremento diacrónico y las primeras que pueden estar relacionadas con la reducción solutrense se han identificado en NV11 (4,3\%) y NV 10 (5,7\%). En estos niveles no existen foliáceos por lo que no hay que descartar que su presencia esté relacionada con la incorporación de materiales desde los cortes abiertos en las campañas de 1960-63. A partir de NV9 la secuencia de reducción solutrense y los restos con tratamiento térmico muestran un incremento significativo, coincidiendo con la primera presencia de foliáceos y piezas con retoque plano (Fig. 1).

En cuanto al utillaje retocado, supone el 13,5\% del total de restos líticos en el conjunto de la Unidad 1 (NV13 - NV11: 98 objetos clasificados) y una media del 10,5\% para la Unidad 2 (NV 10 - NV8: 455 objetos). El proceso de selección de los soportes es mayor en las capas inferiores (NV13 - NV9), apreciando un mayor número y regularidad de soportes laminares que además presentan menos presencia de córtex y los mayores módulos tipométricos (longitud: 40-70 mm). A pesar de la discordancia erosiva que media entre la Unidad 1 (NV13 - NV11) y la base de la 2 (NV10), sus producciones líticas muestran elementos comunes. La presencia de soportes de estilo Vale Comprido se registra a partir de NV12, siempre con un número bajo de efectivos. A partir de NV10 se produce la caída del ya escaso utillaje de dorso y la identificación de una lasca apuntada con retoque simple, sobre un soporte cercano a Vale Comprido (Fig. 3).

La dinámica evolutiva del utillaje retocado está marcada por unos bajos índices del grupo solutrense y la continuidad tecnotipológica con respecto a las producciones gravetienses. La gran mayoría de piezas con retoques someros, truncaduras y utillaje de borde abatido están asociadas a láminas de flanco y de plena talla; los buriles sobre hoja truncada son significativos hasta la capa NV10, mientras que los raspadores sobre lasca sólo serán mayoritarios a partir de
NV8. Este tramo marca un punto de inflexión, produciéndose cierta redistribución tecnotipológica: descenso de la talla laminar, sobre todo de soportes anchos, documentación de una talla microlaminar a partir de núcleos piramidales y prismáticos, aumento de útiles retocados sobre productos de conformación y del utillaje microlaminar de dorso, con ejemplares largos y estrechos más similares a los del Solutrense superior que a los del Magdaleniense inferior.

El utillaje solutrense se reparte entre las puntas de cara plana (10 ejemplares), los fragmentos de foliáceos uni y bifaciales (12 ejemplares), que en 6 casos muestran claros signos de reciclado: 4 con extracciones de buril y 2 como cuñas. Completan la serie solutrense 1 raspador con retoque por presión de NV9, 1 fragmento de hoja de laurel de NV8' y 2 de posibles puntas de escotadura de NV8 y NV8/s (Fig. 3). Es significativa la ausencia de puntas de aletas y pedúnculo, mientras que a las dos puntas de escotadura se debería añadir la descrita por A. Cava (1997), procedente de otro sala. Su distribución por capas se encuentra en la Fig. 1.

En definitiva, la confrontación de los rasgos tecnotipológicos gravetienses y solutrenses indica que en Nerja existe una importante continuidad entre el Gravetiense (NV13 NV11) y el denominado Solutrense A (NV10), un conjunto sin utillaje de dorso y con una cronología más cercana al Protosolutrense que al Solutrense inferior. Las capas NV9 y NV8', nombradas como Solutrense B1 y B2 muestran la presencia de rasgos solutrenses (tratamiento térmico, foliáceos y retoque por presión), pero se mantienen esquemas de tradición gravetiense: producciones laminares sobre frente estrecho y faciales planas, incluyendo algún soporte de estilo Vale Comprido, útiles de tradición gravetiense, como buriles-núcleo multiples sobre truncadura (Fig. 2), piezas esquirladas, incluyendo algún raspador utilizado como cuña, y proyectiles estrechos que recuerdan a las "flechettes"(Fig. 3: 17-18), identificados también en Cova Beneito (Iturbe et al. 1993: 63-64) y Parpalló. El tramo superior (NV8 y NV8/s) muestra rasgos que parecen iniciar un nuevo ciclo que agrupamos como Solutrense C. El descenso de la producción laminar, que ahora marca sus índices más bajos, el aumento de utillaje microlaminar de dorso, obtenido sobre producciones diferenciadas, alguna punta de cara plana y de escotadura conforman sus rasgos básicos (Aura et al. 2006).

\subsection{Cova del Parpalló ¿territorio solutrense $=$ territorio badeguliense?}

La mayoria de yacimientos con estratigrafías largas situados al sur del Ebro presentan procesos erosivos coincidiendo con el final del Solutrense. Este hiato sedimentario tiene su núcleo central en ca. 21-19,5 ka cal BP y afecta a la lectura del proceso de transición y/o sustitución Solutrense - Badeguliense - Magdaleniense (Aura 1995, 2007; Aura et al. 2012). 


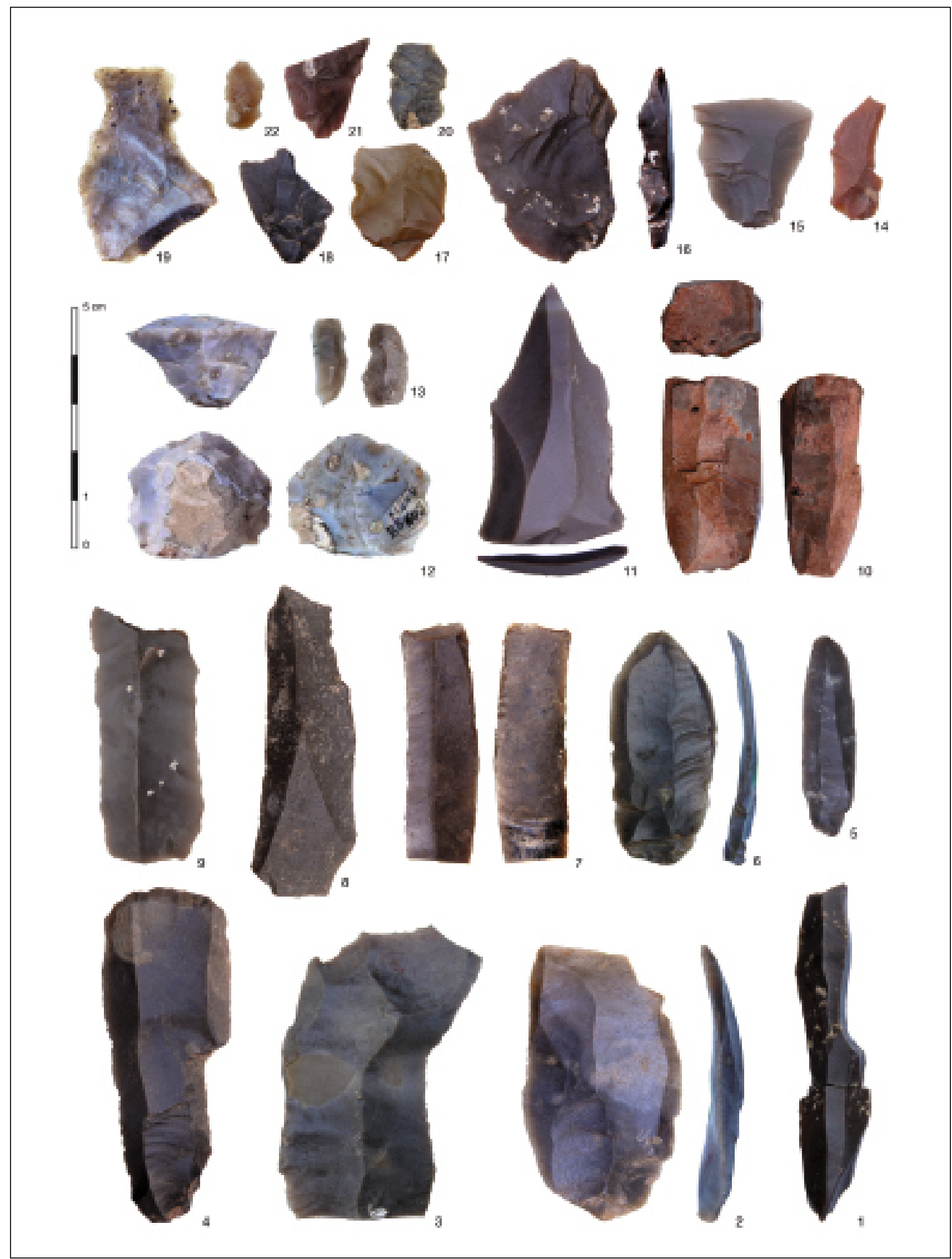

ム Figura 2. Cueva de Nerja, sala del Vestíbulo. Talla laminar de soportes estrechos, anchos y con extracciones convergentes (1-9). Talla microlaminar a partir de núcleo-raspador, núcleo-buril y núcleo prismático (10-13). Facetado y reducción solutrense (14-22). Procedencia: NV13 - NV11 (3-5, 8-9); NV10 (7); NV9 (11-13); NV8' (1, 6, 10, 21-22); NV8 (14-20). 


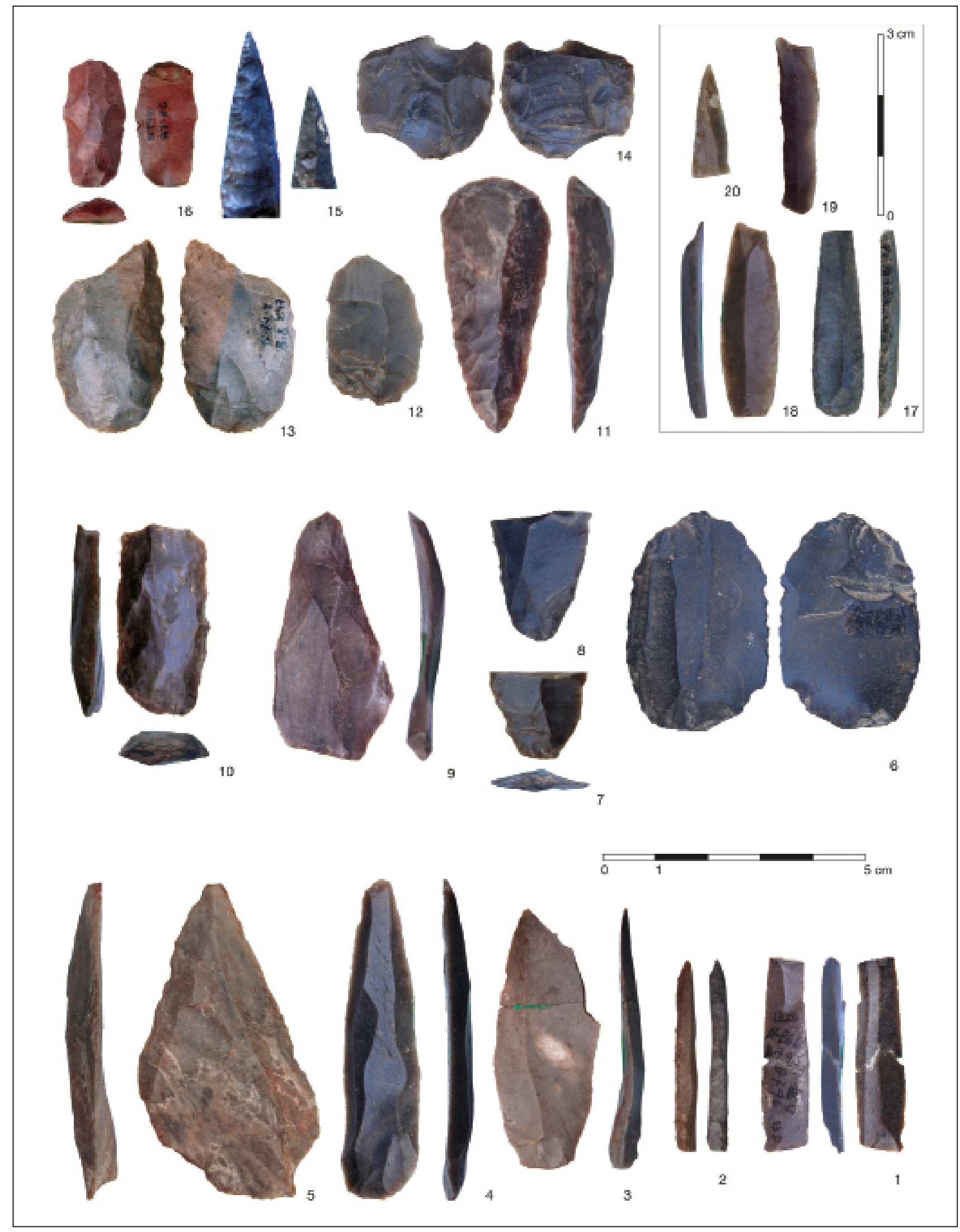

\ Figura 3. Cueva de Nerja, sala del Vestíbulo. Puntas gravetienses y utillaje solutrense. Posible proyectil con fractura de impacto, sin retoque (1); punta de dorso (2); soportes de estilo Vale Comprido $(3-5,7,9)$; puntas de cara plana $(8,10,13,16)$; raspador esquirlado (6); raspador solutrense (11); raspador ojival (12); hoja de laurel (14); extremos distales de ¿puntas de escotadura? (15 y 20); posibles puntas de tradición gravetiense (17-18); hojita de dorso (19). Procedencia: NV13 - NV11 (1-4); NV10 (5); NV9 (7, 9-11); NV8' (8); NV8 (6, 12-14, 16, 18-20); NV 8/s $(15,17)$. 
La variabilidad regional de puntas de piedra solutrense se transformó en una producción más expeditiva, a base de láminas cortas, lascas y también microláminas y microlascas, recibiendo diferentes denominaciones: Protomagdaleniense I, Magdaleniense 0, antiguo y Badeguliense que es la denominación que recientemente parece suscitar más consenso (Crétin 2007; Bodu et al. 2007; Ducasse 2010). Esto ocurrió sólo en lo que fue el "territorio solutrense", pues una parte sustancial de estos rasgos son compartidos por los conjuntos situados al $\mathrm{N}$ y $\mathrm{S}$ de los Pirineos, aunque se empieza a plantear un uso restrictivo del término Badeguliense (Banks et al. 2011: 361). También parece común el notable aumento de la industria ósea, identificando convergencias técnicas y temas decorativos (Aura 2007).

En Iberia estas industrias "a caballo" entre el Solutrense y el Magdaleniense han recibido también diferentes denominaciones Magdaleniense arcaico, inicial o antiguo, Fase magdalenizante, Solutrense des-solutreanizado y $\mathrm{Ba}-$ deguliense (Utrilla 1981 y 2006; Fullola Pericot 1979; Corchón 1981; de la Rasilla 1994; Straus 1983; Aura 1995; Zilhão 1997; Bosselin y Djindjian 1999). Posiblemente, existen elementos regionales por detallar.

El proceso de transformación de las estructuras tecnoeconómicas solutrenses sólo ha podido ser analizado en Parpalló, reconociendo una pérdida de las producciones laminares y microlaminares clásicas, obtenidas a partir de núcleos prismáticos explotados en volumen y cuyos soportes fueron utilizados para elaborar los últimos foliáceos, las puntas de escotadura, truncaduras, buriles y utillaje microlaminar (Tiffagom 2006).

Paralelamente, se observa un incremento de lo que hemos denominado como caracteres badegulienses que incluyen tanto estrategias de producción como útiles retocados propios. Es el caso del aumento de láminas y lascas indeterminadas a partir de núcleos multifacetados, la producción de láminas cortas y anchas y también de una talla discoide, facial y levallois (Bracco et al. 2003; Crétin et al. 2007), que vienen a reemplazar los esquemas laminares-microlaminares clásicos. Estos soportes serán utilizados, básicamente, como utillaje doméstico (raspadores cortos, bécs, raederas, piezas con retoques simples y semiabruptos o las primeras rasquetas). Por último, están documentados también los núcleos carenados y diferentes variantes organizadas a partir de la cara inferior o desde fracturas sobre lascas espesas. Se trata de núcleos-raspadores (Bodu 2005), núcleos sobre frente dorsal (Ducasse y Langlais 2007) y núcleos-buriles (Le BrunRicalens y Brou 2003), aunque sólo se han reconocido unas pocas microlaminitas, ya que estos soportes no están bien documentados en las excavaciones antiguas. Estas producciones suponen ya el $40 \%$ del total de la industria lítica del Magdaleniense I de Pericot (3,75 - 3,50 m), considerado como Episolutrense (Aura 1995), o como la "transición" (Aura et al. 2012).
La "visibilidad" de este proceso de transformación tecno-económica en la región mediterránea ibérica ha estado velada por la actuación de procesos sedimentarios erosivos. También por la autoridad de la propuesta de Pericot (1942) sobre el Magdaleniense de Parpalló, apoyada sobre la evolución de las industrias óseas y su relación con las fases establecidas por Breuil (1912) para el suroeste francés. La combinación de ambos elementos convirtió a Parpalló en una especie de "colonia magdaleniense" (Jordá 1958), pues en ningún otro yacimiento se reconocia la asociación de sus materiales ni sus fases.

En Parpalló se identificaron unos potentes tramos estratigráficos con ocupaciones badegulienses y también en Volcán del Faro (Aura 1995; Vadillo 2012; Soler et al. 2013), lo que contrasta con su ausencia en otros sitios más o menos cercanos. Sin embargo, en diferentes yacimientos se identifican "útiles badegulienses" característicos:

- Láminas cortas-anchas y lascas clasificadas entre las piezas con retoque continuo, raederas, muescas o denticulados. En más del 50\% de piezas de estos grupos presentan combinaciones con retoques inversos y alternos, (Aura 1995: 86-87).

- Perforadores y bécs simples de silueta triangular (¿puntas con retoques alternos?)

- Rasquetas y microútiles sobre lascas de tipo "kombewa", con sección en perfil cóncavo y con retoque semiabrupto.

Estos "morfotipos" elaborados con retoque $S$ y $S(A)$ representan en Parpalló-Talut más del $41 \%$ en las capas de T/11 a T/6, aunque la ausencia de utillaje microlaminar sobredimensiona su frecuencia. Estos valores pueden duplicarse al sumar los raspadores de algunas capas. Por tanto, el final del Solutrense está asociado a sistemas de producción lítica más expeditiva y un utillaje de orientación quizás más doméstica; una interpretación que es tecnomorfológica, puesto que se carece del soporte de estudios traceológicos.

En la Figura 4 se muestran estos morfotipos identificados en yacimientos donde no se han reconocido ocupaciones badegulienses, pero si estos útiles en contextos del Solutrense superior.

- Es el caso de los niveles BB1 y BB2 de Barranc Blanc, considerados como Magdaleniense inicial Solutreogravetiense (Fullola Pericot 1979: 196).

- En los niveles III y II de la cata Este (1970) de Les Malladetes se dibujan también algunos morfotipos (Fortea y Jordá 1976: fig. 7), que en el diario de excavaciones se amplian: al menos 6 rasquetas y 5 lascas con retoques alternos y algún perforador. 


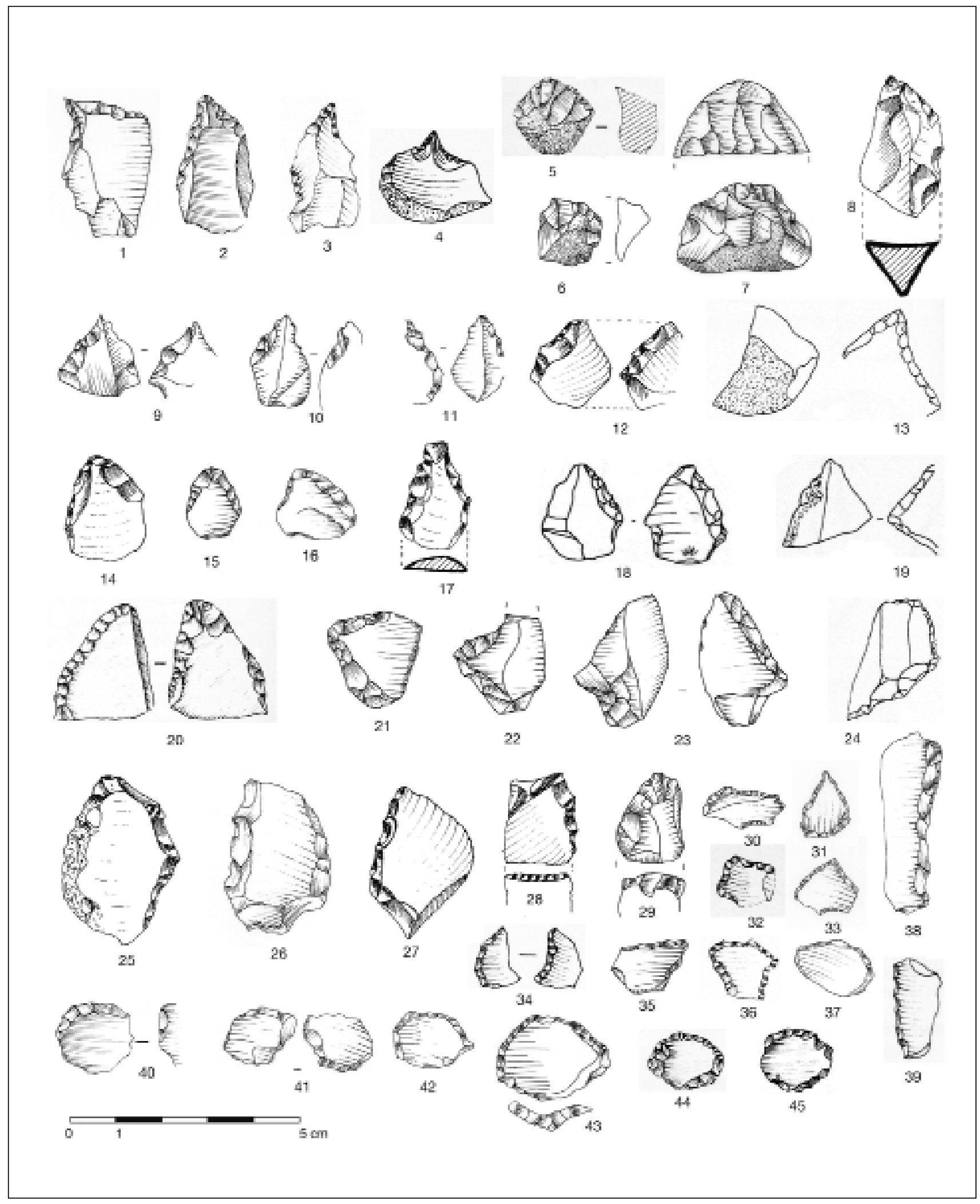

\ FIgURA 4. Útiles identificados como badegulienses. Perforadores (1-4), bécs triangulares con retoques alternos o ¿proyectiles? (1-4, 9-13, 19); Núcleos-raspadores (5-8); Piezas retocadas y microraederas con retoque inverso (14-17, 21, 26-28), directo $(22$, 25) y alterno $(18,20,23,29)$; Microútiles con retoques semiabruptos cortos y rasquetas (30-37, 42-45), con retoques alternos (40-41); Soportes largos y estrechos con retoque inverso (38-39). Procedencia: Parpalló-Talut $5(1,16,26,31,33,38,41)$; Parpalló-Talut 6 (37, 42); Parpalló-Talut $7(11,29,30,35,43)$; Parpalló-Talut $8(6,9,10)$; Parpalló-Talut $9(7,15,21-23)$; Volcán del Faro c.8 (8, 17); Volcán del Faro c. $11(12,14,25,27,28)$; Malladetes II (2); Malladetes III $(5,20,40,44,45)$; Barranc Blanc $1(4,34)$ Barranc Blanc 2 (3, 32, 36, 39) Cova de les Cendres XIIB (18, 19, 24), XIII (13). (Fuentes: Aura 1995; Aparicio 2003; Fortea y Jordá 1976; Fortea Pérez 1973; Villaverde et al. 1999). 
- En Cendres se han identificado los problemas estratigráficos de este episodio y al describir el nivel XIII (Solutrense superior) se señala que "inciden numerosos procesos erosivos (...) un buzamiento de los paquetes contrario a la tendencia general (...) y un alto índice de bioturbación" (Villaverde et al. 2010: 87). Pues bien, en la base del nivel XII se obtuvo una datación coincidente con las aceptadas para el Solutrense evolucionado (17230 \pm 130 BP) que se considera pueda corresponder al nivel XIII. En ambos niveles XIIB y XIII se reconocen algunos útiles que encajan en la descripción de badegulienses (Villaverde et al. 1999: Fig. 9, 14, 16, 22, 24; Fig. 10, 8-10).

- En Cova Beneito no se reconocen estos morfotipos, pero sí un alto índice de útiles del sustrato en B1 (Iturbe et al. 1993), que en el sector exterior es todavía mayor y con una datación que se relaciona con el Solutreogravetiense (Nivel II: $16180 \pm 140$ ) (Domenech et al. 2012)

- Por último, de la Cueva de Maltravieso (Cáceres) se ha publicado un reducido conjunto de artefactos líticos en el que destaca el empleo de materias primas locales y la identificación de una rasqueta ( $\mathrm{Ca}$ nals et al. 2010). No existen elementos solutrenses, pero la cronología radiocarbónica abre una relación con el Badeguliense.

\section{LAS EDADES SOLUTRENSES}

Se han recopilado las referencias sobre la cronología radiocarbónica para el territorio situado entre el sur de la margen derecha del Ebro, el sistema Central y la margen izquierda del Guadiana hasta la Punta de Tarifa, sin incluir por tanto la facies atlántica portuguesa. El rango temporal seleccionado abarca entre 26,5 y 15,5 ka BP (31,5 - 18 ka cal BP), identificando 75 fechas procedentes de 21 sitios: Aragón (3), Castilla - La Mancha (2), Extremadura (1), País Valenciano (6), Murcia (2), Andalucía (7), más el caso de Gorham's Cave. Las fechas han sido evaluadas antes de proceder a su calibración, aplicando los siguientes criterios (Tab. 1):

- Sólo se consideran las datas obtenidas mediante ${ }^{14} \mathrm{C}$ convencional y AMS. Posiblemente, a esta diferenciación habrá que añadir en un futuro las obtenidas a partir de muestras con tratamientos previos (Longin o ABA, por ejemplo) (Higham 2011).

- No se utilizan las fechas obtenidas sobre carbones utilizados como pigmentos y puntos de iluminacion (Tab. 1).

- Se han descartado aquellas que ofrecen resultados anómalos y contradicciones estratigráficas; esta situación es compleja cuando existen dos o más dataciones para un mismo nivel (Gorham's III-B o algunos de los de Nerja y Cueva Ambrosio). En estos

\begin{tabular}{|c|c|c|c|c|c|c|c|c|c|c|c|}
\hline Yacimiento / capa & Ref. Lab. & $\begin{array}{c}\text { Fecha } \\
\text { BP }\end{array}$ & SD & Método & Material & $\begin{array}{c}\text { Edad cal } \\
\text { BP }(95 \%) \\
\{0=A D 1950\}\end{array}$ & Fase & UA & Referencia & Fig. 5 & Fig. 6 \\
\hline Alexandre IIIb & GrN-23448 & 15370 & 110 & $14 \mathrm{C}$ convencional & C & $18930-17850$ & $\mathrm{Ml}$ & 7 & Utrilla et al., 2006 & & \\
\hline Cendres XII & Beta-287540 & 15630 & 60 & 14C AMS & C & $18830-18670$ & MI & 7 & Villaverde et al., 2012 & & \\
\hline Cendres XII & Ly-5586 & 15820 & 150 & $14 \mathrm{C}$ convencional & C & $19270-18630$ & $\mathrm{Ml}$ & 7 & Villaverde et al., 1999 & & \\
\hline Cendres XII & Beta-287541 & 16030 & 60 & 14C AMS & C & $19340-18900$ & MI & 7 & Villaverde et al., 2012 & & \\
\hline Gato-2 & GrA-42226 & 17700 & 70 & 14C AMS & $\mathrm{H}$ & $21440-21040$ & MA & 7 & Blasco y Rodanés, 2004 & & \\
\hline Maltravieso A & Poz-30469 & 17840 & 90 & 14C AMS & C & $21550-21190$ & $\mathrm{BA}$ & 6 & Canals et al., 2010 & & \\
\hline Maltravieso A & Poz-30460 & 17930 & 100 & 14C AMS & C & $21630-21270$ & BA & 6 & Canals et al., 2010 & & \\
\hline Parpalló T-11 & $0 \times A-22629$ & 18510 & 100 & 14C AMS & C. pyrenaica & $22700-21780$ & BA & 6 & Aura et al., 2012 & & \\
\hline Gato-2 & GrA-22505 & 18650 & 140 & 14C AMS & C & $22800-22160$ & MA & 6 & Blasco y Rodanés, 2004 & & \\
\hline Beneito II (ext) & Ua-32243 & 16180 & 140 & 14C AMS & $\mathrm{H}$ & $19820-18900$ & SG & 5 & Domenech et al., 2012 & & \\
\hline La Boja (SW18B2) & Vera-5364-a & 16990 & 70 & 14C AMS & Juniperus sp. & $20580-20260$ & SG & 5 & Lucena et al., 2012 & & \\
\hline Ratlla del Bubo II & Ly-5219 & 17360 & 180 & $14 \mathrm{C}$ convencional & C & $21310-20390$ & SG & 5 & Soler et al., 1990 & & \\
\hline La Boja (SW18B2) & Vera-5364-b & 17430 & 70 & 14C AMS & Juniperus sp. & $21150-20710$ & SG & 5 & Lucena et al., 2012 & & \\
\hline Parpalló 4-4,25m & Birm-521 & 17896 & 340 & 14C convencional & $\mathrm{H}$ & $22570-20570$ & SG & 5 & $\begin{array}{l}\text { Bofinger and Davidson, } \\
\qquad 1977\end{array}$ & & \\
\hline Nerja 8c & UBAR 98 & 17940 & 200 & $14 \mathrm{C}$ convencional & C & $22190-20990$ & ¿SG? & 5 & Jordá et al., 1990 & & \\
\hline Cendres XIlbase & Beta 118024 & 17230 & 130 & 14C AMS & Pinus nigra & $21010-20370$ & SG & 5 & Villaverde et al., 1999 & & \\
\hline Beneito IV (ext) & Ua-32243 & 18275 & 175 & 14C AMS & $\mathrm{H}$ & $22580-21380$ & SE & 5 & Domenech et al., 2012 & & \\
\hline Gorham's Cave III-B & Beta-184042 & 18440 & 160 & 14C AMS & C & $22700-21540$ & SE & 4 & Finlayson et al., 2006 & & \\
\hline Cendres XIIIB & Beta-118027 & 18750 & 130 & 14C AMS & Pinus nigra & $22860-22380$ & SE & 4 & Villaverde et al., 1999 & & \\
\hline Cendres XIII & Beta-118026 & 18920 & 180 & 14C AMS & Pinus nigra & $23250-22410$ & SE & 4 & Villaverde et al., 1999 & & \\
\hline Parpalló T-16 & $0 \times A-22651$ & 19020 & 100 & 14C AMS & C. pyrenaica & $23230-22590$ & SG & 4 & Aura et al., 2012 & & \\
\hline Ambrosio II.4 & Gif-A-II.4 & 19110 & 90 & 14C AMS & C & $23300-22700$ & SE & 4 & Ripoll et al., 2004 & & \\
\hline Ambrosio II.2 & Gif-A-II.2 & 19170 & 190 & 14C AMS & C & $23470-22590$ & SE & 4 & Ripoll et al., 2004 & & \\
\hline
\end{tabular}




\begin{tabular}{|c|c|c|c|c|c|c|c|c|c|c|c|}
\hline Yacimiento / capa & Ref. Lab. & $\begin{array}{c}\text { Fecha } \\
\text { BP }\end{array}$ & SD & Método & Material & $\begin{array}{c}\text { Edad cal } \\
\text { BP }(95 \%) \\
\{0=A D 1950\}\end{array}$ & Fase & UA & Referencia & Fig. 5 & Fig. 6 \\
\hline $\begin{array}{l}\text { Rambla Perea FDM } \\
4-5\end{array}$ & $\begin{array}{l}\text { VERA- } \\
5101 b H S\end{array}$ & 19180 & 90 & $14 \mathrm{C}$ AMS & Juniperus sp. & $23350-22790$ & SE & 4 & Zilhao et al., 2010 & & \\
\hline Ambrosio II g & GifA 9883 & 19250 & 70 & 14C AMS & C & $23380-22940$ & SE & 4 & Ripoll et al., 2004 & & \\
\hline Ambrosio II.6 & Gif-A-II.6 & 19300 & 190 & $14 \mathrm{C}$ AMS & C & $23560-22720$ & SE & 4 & Ripoll et al., 2004 & & \\
\hline La Boja (SW18C) & Vera-5365 & 19390 & 100 & 14C AMS & Juniperus sp. & $23490-23090$ & SE & 4 & Lucena et al., 2012 & & \\
\hline Ambrosio Il.1 & GifA-95577 & 19950 & 210 & 14C AMS & C & $24460-23340$ & $\mathrm{SE}$ & 4 & Ripoll et al., 2004 & & \\
\hline Ambrosio II.1 & GifA-95576? & 20150 & 200 & 14C AMS & C & $24640-23560$ & SE & 4 & Ripoll et al., 2004 & & \\
\hline Ambrosio IV & Gif- 9884 & 21520 & 120 & $14 \mathrm{C}$ convencional & C & $26070-25030$ & SE & 4 & Ripoll et al., 2004 & & \\
\hline Santa Maira II-12 & Beta-317412 & 19910 & 100 & 14C AMS & $\begin{array}{l}\text { P. nigra- } \\
\text { sylvestris }\end{array}$ & $24010-23490$ & $\mathrm{~s}$ & 3 & Este trabajo & & \\
\hline Peña Capón -3 & Beta-246879 & 19980 & 110 & 14C AMS & $\mathrm{H}$ & $24240-23520$ & $\mathrm{~s}$ & 3 & Alcaraz-Castaño, 2013 & & \\
\hline La Boja (SW18E) & Vera-5213 & 20980 & 110 & 14C AMS & Juniperus $s p$. & $25100-24740$ & $\mathrm{SI}$ & 2 & Lucena et al., 2012 & & \\
\hline La Boja (SW18E) & Vera-5366 & 20980 & 120 & 14C AMS & Juniperus sp. & $25130-24730$ & $\mathrm{SI}$ & 2 & Lucena et al., 2012 & & \\
\hline Nerja NV 9 (C4 VIII) & GifA 102021 & 21140 & 190 & 14C AMS & Pinus pinea & $25770-24650$ & $\mathrm{SI}$ & 2 & Jordá y Aura, 2008 & & \\
\hline Peña Capón -4 & Beta-246878 & 21220 & 120 & 14C AMS & H & $25720-24800$ & $\begin{array}{l}\text { Pro- } \\
\text { Sol }\end{array}$ & 2 & Alcaraz-Castaño, 2013 & & \\
\hline Cendres XIV & Beta- 14283 & 21230 & 180 & $14 \mathrm{C}$ AMS & Pinus nigra & $25840-24760$ & G & 1 & Villaverde y Román, 2004 & & \\
\hline El Palomar III & Beta-185409 & 21560 & 110 & 14C AMS & $\mathrm{H}$ & $26100-25100$ & $\mathrm{G}$ & 1 & de la Peña, 2011 & & \\
\hline Nerja V 13 & BETA-131576 & 24480 & 110 & 14C AMS & C & $29850-29170$ & G & 1 & Jordá y Aura, 2008 & & \\
\hline Cendres XVIA & Beta-155606 & 24080 & 150 & 14C AMS & Pinus nigra & $29660-28260$ & G & 1 & Villaverde y Román, 2004 & & \\
\hline Nerja V 13 & BETA-189080 & 24200 & 200 & 14C AMS & Pinus pinea & $29820-28300$ & G & 1 & Jordá y Aura, 2008 & & \\
\hline Cendres XVIA & Beta-14284 & 24240 & 220 & 14C AMS & Pinus nigra & $29890-28290$ & G & 1 & Villaverde y Román, 2004 & & \\
\hline Malladetes & Beta & 25120 & 240 & 14C AMS & P. cf. nigra & $30450-29650$ & $\mathrm{G}$ & 1 & Arsuaga et al., 2001 & & \\
\hline Nerja V 12 & GifA 102023 & 24730 & 250 & $14 \mathrm{C}$ AMS & Pinus pinea & $30140-29180$ & G & 1 & Jordá y Aura, 2008 & & \\
\hline Ángel 1/ 10 & GrA-16961 & 25330 & 190 & 14C AMS & $\mathrm{C}$ & $30580-29780$ & G & 1 & Utrilla et al., 2003 & & \\
\hline Cendres XVIC & Beta-189078 & 25850 & 260 & $14 \mathrm{C}$ AMS & Pinus nigra & $31530-30050$ & G & 1 & Villaverde y Román, 2004 & & \\
\hline El Palomar IV & Beta-185410 & 26430 & 210 & 14C AMS & $\mathrm{H}$ & $31850-30690$ & G & 1 & Vega y Martin, 2006 & & \\
\hline Descartadas & & & & & & Observaciones & & & & & \\
\hline Nerja NV9a & UBAR-344 & $\begin{array}{c}> \\
9000\end{array}$ & & 14C convencional & C & Anómala & $\mathrm{s}$ & & Aura et al., 1998 & & \\
\hline Nerja NV8-i & Beta-189081 & 12360 & 60 & 14C AMS & Pinus pinea & Percolación & $S$ & & Jordá y Aura, 2008 & & \\
\hline Nerja NV 9 (C4 VIII) & GifA-102020 & 12550 & 100 & 14C AMS & Mytilus edulis & Anómala & $\mathrm{s}$ & & Jordá y Aura, 2008 & & \\
\hline Carihuela IV-3-III & Pta-7982 & 15700 & 220 & 14C convencional & Sedimento & Contexto & $\mathrm{M}$ ? & & Carrión et al., 1998 & & \\
\hline Nerja $8 \mathrm{i}$ & UBAR-157 & 15990 & 260 & 14C convencional & $\mathrm{C}$ & Anómala & $\mathrm{S}$ & & Jordá et al., 1990 & & \\
\hline Malladetes III & KN-I/918 & 16300 & 1500 & $14 \mathrm{C}$ convencional & $\mathrm{C}$ & SD & SE & & Fortea y Jordá, 1976 & & \\
\hline Gorham's Cave III-B & Beta-181893 & 16420 & 120 & 14C AMS & C & 20 más datas & SE & & Finlayson et al., 2006 & & \\
\hline Ambrosio II & Gif-7276 & 16500 & 280 & 14C convencional & $\mathrm{C}$ & 20 más datas & SE & & Ripoll López, 1988 & & \\
\hline Nerja M79/8 & GAK-8965 & 16520 & 540 & 14C convencional & C & Anómala & $S ?$ & & Pellicer y Acosta, 1997 & & \\
\hline Beneito B2 & Ly-3596 & 16560 & 480 & $14 \mathrm{C}$ convencional & $\mathrm{H}$ & SD & SE & & Iturbe y Cortell, 1987 & & \\
\hline Ambrosio VI & Gif-7277 & 16590 & 1400 & $14 \mathrm{C}$ convencional & $\mathrm{C}$ & SD & $\mathrm{S}$ & & Ripoll López, 1988 & & \\
\hline Ambrosio IV & Gif-7275 & 16620 & 280 & 14C convencional & C & 20 más datas & SE & & Ripoll López, 1988 & & \\
\hline Parpalló 5-4,5m & BM-861 & 18080 & 800 & 14C convencional & $\mathrm{H}$ & SD & SE & & $\begin{array}{c}\text { Bofinger \& Davidson, } \\
1977\end{array}$ & & \\
\hline Nerja 8k-I & UBAR 158 & 18420 & 530 & $14 \mathrm{C}$ convencional & C & SD & $S$ & & Jordá et al., 1990 & & \\
\hline Parpalló 5,25-4,5 & BM-861 & 18800 & $850 / 750$ & 14C convencional & $\mathrm{H}$ & SD & $S$ & & Fullola Pericot, 1979 & & \\
\hline Bajondillo/ 9 & AA-34710 & 19990 & 480 & 14C AMS & $\mathrm{H}$ & SD & $S$ & & Cortés Sánchez, 2007 & & \\
\hline Parpalló 7,25-6,25 & Birm-520 & 20166 & 380 & $14 \mathrm{C}$ convencional & $\mathrm{H}$ & SD & $\mathrm{SI}$ & & $\begin{array}{c}\text { Bofinger \& Davidson, } \\
1977\end{array}$ & & \\
\hline Parpalló 7,25-6,25 & BM-859 & 20490 & $900 / 850$ & 14C convencional & $\mathrm{H}$ & SD & $\mathrm{SI}$ & & $\begin{array}{c}\text { Bofinger \& Davidson, } \\
1977\end{array}$ & & \\
\hline Higueral de Valleja -V & 12270 & 20780 & 80 & 14C AMS & C & Contexto & G & & Jennings et al., 2009 & & \\
\hline No utilizadas & & & & & & Observaciones & & & & & \\
\hline Nerja- ciervo & GifA-98191 & 19900 & 210 & 14C AMS & C & Arte & $S$ & & Sanchidrián et al., 2001 & & \\
\hline Pileta- uro & GifA-98162 & 20130 & 350 & 14C AMS & C & Arte & $S$ & & Sanchidrián et al., 2001 & & \\
\hline Nerja (220) & Beta-271212 & 20980 & 100 & 14C AMS & $\mathrm{C}$ & Iluminación & S? & & Medina et al., 2010 & & \\
\hline Nerja (Concav. 15) & Beta-271211 & 23800 & 140 & 14C AMS & C & Iluminación & S? & & Medina et al., 2010 & & \\
\hline
\end{tabular}




\begin{tabular}{|c|c|c|c|c|c|c|c|c|c|c|c|}
\hline Yacimiento / capa & Ref. Lab. & $\begin{array}{c}\text { Fecha } \\
\text { BP }\end{array}$ & SD & Método & Material & $\begin{array}{c}\text { Edad cal } \\
\text { BP }(95 \%) \\
\{0=\text { AD 1950 }\}\end{array}$ & Fase & UA & Referencia & Fig. 5 & Fig. 6 \\
\hline Nerja (111-156) & Beta 277744 & 24130 & 140 & 14C AMS & C & Iluminación & $\mathrm{S} ?$ & & Medina et al., 2010 & & \\
\hline Bajondillo/ 7 & MAD-3927 & 16438 & 1497 & TL & carbonatos & & SG & & Cortés Sánchez, 2007 & & \\
\hline Bajondillo/ 8 & MAD-3926 & 17582 & 1521 & TL & carbonatos & & SG & & Cortés Sánchez, 2007 & & \\
\hline Bajondillo/ 9 & MAF-2405 & 18701 & 2154 & TL & silex & & SE & & Cortés Sánchez, 2007 & & \\
\hline Bajondillo/ 10 & MAD-2470 & 24344 & 2653 & TL & silex & & G & & Cortés Sánchez, 2007 & & \\
\hline
\end{tabular}

\ Tabla 1. Listado de las dataciones radiocarbónicas utilizadas y descartadas para este trabajo. Abreviaturas empleadas: Material: C (carbón), H (hueso); Fases: G Gravetiense; Pro-Sol: Proto-solutrense; SI: Solutrense inferior; S: Solutrense pleno; SE: Solutrense evolucionado; SG: Solutreogravetiense; MA: Magdaleniense arcaico; BA: Badeguliense; MI: Magdaleniense inferior; UA (= unidades arqueológicas) su numeración se corresponde con las 7 fases anteriores. En las columnas denominadas como Fig. 5 y 6 se indican las fechas utilizadas para elaborar las curvas de probabilidad de las fechas calibradas de las Figs. 5 y 6 . Las fechas calibradas han sido obtenidas utilizando la curva CalPal 2007 Hulu (Weninger et al. en línea) incluida en el programa CalPal Version March 2007 (Weninger y Jöris 2004).

casos se ha seleccionado la que se considera "más coherente" con los materiales asociados, aceptando el sesgo de la elección.

- No se han calibrado aquellas fechas con datos preliminares sobre el contexto o con un grado de incertidumbre razonable, expresado por los mismos autores (casos de Higueral o Carihuela). Sin embargo, si se han considerado las obtenidas en La Boja (Zilhão et al. 2010; Lucena et al. 2012) y Cova Beneito (Doménech et al. 2012) puesto que como se verá, inciden sobre la cuestión de la "cronología larga".

- Por último, se han rechazado aquellas fechas con una desviación típica superior a 350 años.

Tras la aplicación de estos criterios, las 75 fechas iniciales han quedado reducidas a 47 (6 de ${ }^{14} \mathrm{C}$ y 41 de AMS), agrupadas en siete unidades de análisis: (1) Gravetiense; (2) Protosolutrense - Solutrense inicial; (3) Solutrense pleno; (4) Solutrense evolucionado; (5) Solutreogravetiense; (6), Badeguliense / Magdaleniense arcaico; (7) Magdaleniense inferior. Para su calibración hemos utilizado la curva CalPal 2007 Hulu (Weninger et al. en línea) incluida en el programa CalPal Version March 2007 (Weninger y Jöris 2004) con el fin de obtener las curvas de probabilidad acumulada con la máxima probabilidad de las fechas radiocarbónicas de las seis unidades arqueológicas consideradas a lo largo del texto (Fig. 5).

Las datas del Solutrense evolucionado (con foliáceos y retoque por presión) y Solutreogravetiense (con puntas escotadas de retoque abrupto) han permitido un análisis específico. Se han aplicado los criterios descritos hasta ahora, excepto el referido a la selección de una datación en el caso de disponer de varias para un mismo nivel arqueológico. Por tanto, para elaborar esta curva se han calibrado todas, sin descartar ninguna de las que tienen una SD inferior a 350 años (Fig. 6). En la Tabla 1 se indican las 24 dataciones de conjuntos con puntas pedunculadas y de escotadura, que se han utilizado para elaborar dos curvas en este caso, pues se compara la obtenida mediante $14 \mathrm{C}$ convencional ( 6 dataciones) y AMS (18 de dataciones).

\subsection{Gravetiense final, Protosolutrense e inicio del Solutrense}

Cuatro contextos datados entre 21,2 - 21 ka BP (25,7 24,8 ka cal BP) pueden servir para plantear esta primera cuestión, aunque no resulta sencillo. Se trata de sitios bastante alejados entre sí, con un volumen de información desigual y atribuciones arqueológicas diversas.

- Cueva Ambrosio IV ofrece la cronología más alta. Sus materiales han sido considerados como Solutrense superior a partir de un buen conjunto de hojas de laurel, foliáceos y alguna punta de cara plana a las que se añaden la presencia de puntas de aletas y pedúnculo y escotadura (Ripoll et al. 2006). Su relación con el Gravetiense no parece viable.

- En Cendres XIV se ha descrito un conjunto reducido de materiales relacionado con el Gravetiense final, aunque la identificación de un canal erosivo colmatado plantea reservas sobre la muestra (Villaverde et al. 2004). El conjunto es reducido, destacando una punta tipo Cendres y otra de cara plana rota de características evolucionadas.

- En Peña Capón 3, se acaba de describir un conjunto Protosolutrense con núcleos prismáticos planos, núcleo-raspadores y 13 puntas de tipo Vale Comprido (Alcaraz-Castaño et al. 2013).

- En Nerja, la data del sondeo (C4, VIII) se corresponde con NV9 y parte de NV10 de la secuencia arqueológica general. NV10 fue considerado como Solutrense $A$, más por la caída de los abruptos que por los rasgos solutrenses, pues se identifican soportes tipo Vale Comprido y alguna punta, pero no retoque 


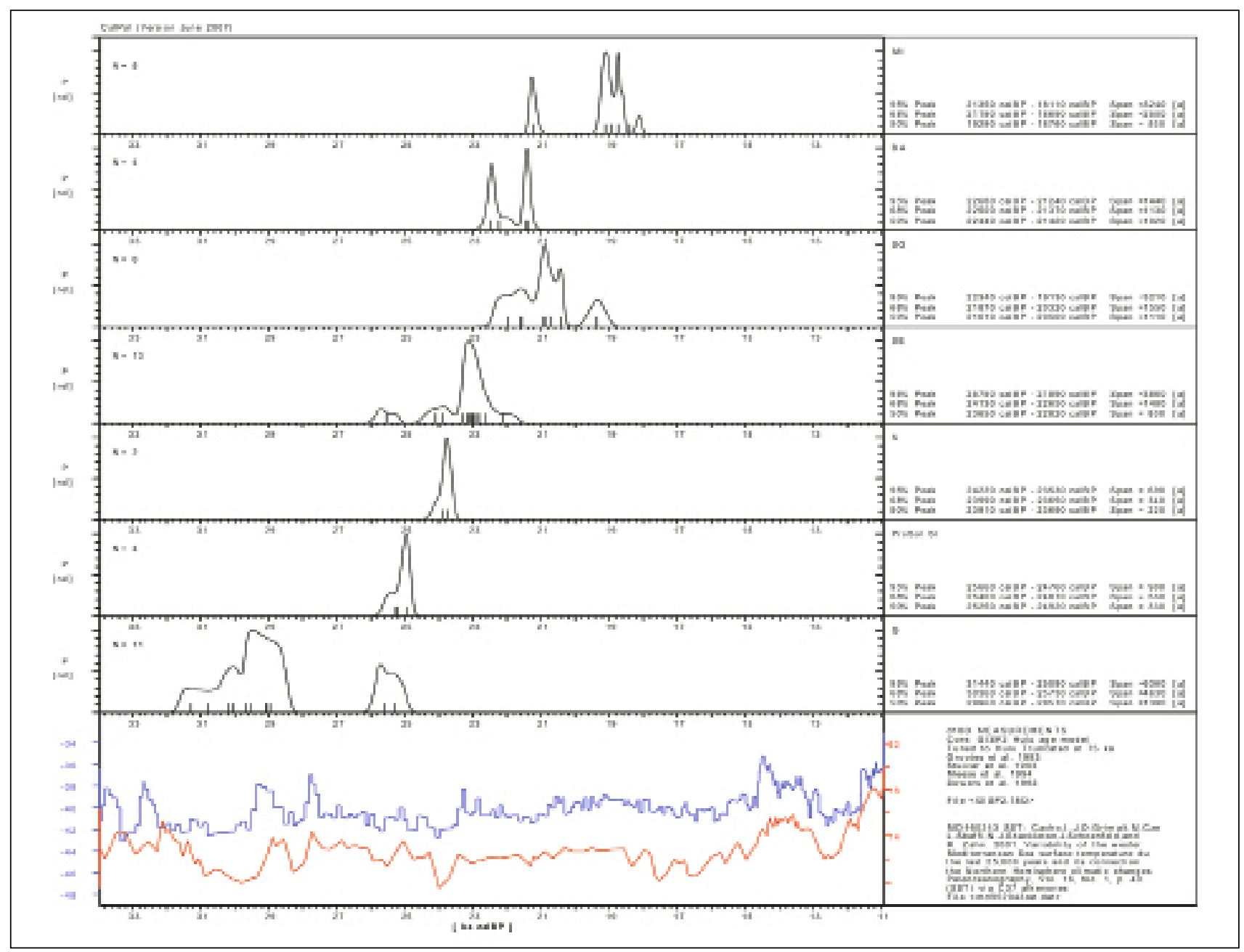

\ FiguRA 5. Curvas de probabilidad acumulada de las fechas calibradas de las seis unidades arqueológicas definidas en el texto, obtenidas utilizando la curva CalPal 2007 Hulu (Weninger et al. en línea) incluida en el programa CalPal Version March 2007 (Weninger y Jöris 2004). Las proxies paleoclimáticas de referencia son las curvas $\delta 180$ GIaSP2 Hulu Age Model (Grootes et al. 1993; Meese et al. 1994; Wang et al. 2001) y SST MD95-2043 del mar de Alborán (Cacho et al. 1999, 2001).

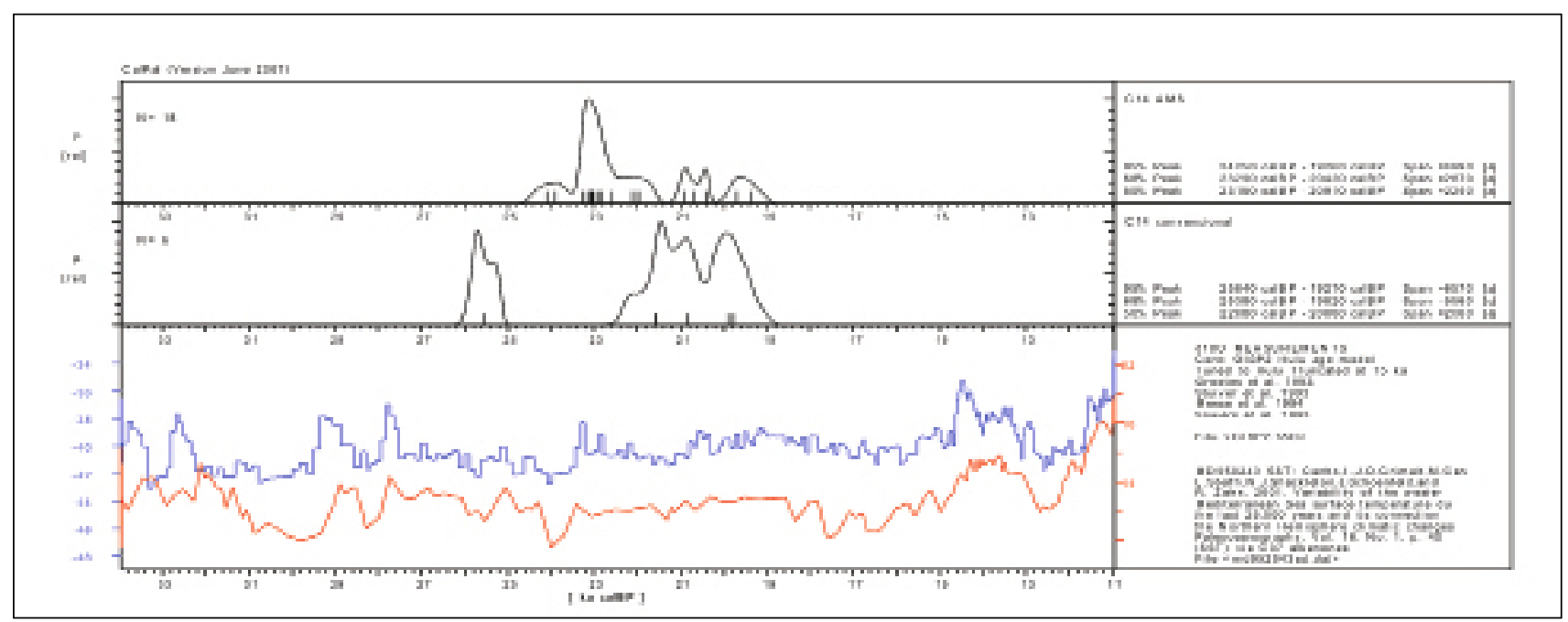

A FiguRA 6. Comparación entre las curvas de probabilidad acumulada de las fechas calibradas del Solutrense superior y del Solutreogravetiense obtenidas mediante 14C convencional y AMS, utilizando la curva CalPal 2007 Hulu (Weninger et al. en línea) incluida en el programa CalPal Version March 2007 (Weninger y Jöris 2004). Las proxies paleoclimáticas de referencia son las curvas $\delta 180$ GISP2 Hulu Age Model (Grootes et al. 1993; Meese et al. 1994; Wang et al. 2001) y SST MD95-2043 del mar de Alborán (Cacho et al. 1999, 2001). 
por presión. NV9 contiene dos puntas de cara plana y los primeros foliáceos (Aura et al. 2006).

Estos datos indican que en los conjuntos con datas más antiguas se describen morfotipos evolucionados (las puntas pedunculadas y escotadas de Ambrosio IV, o la de cara plana de Cendres XIV). Mientras que los que ofrecen las fechas más recientes contienen puntas de Vale Comprido (Peña Capón 4), o soportes similares y puntas de cara plana (Nerja: NV10 y NV9). El reconocimiento de un horizonte Protosolutrense en el centro peninsular aproxima los procesos tecno-económicos identificados en la Extremadura portuguesa, el suroeste francés y la región ibérica; pero persisten elementos regionales que será necesario considerar.

\subsection{El Solutrense}

Entre $i 20,5$ ? y 18,5 ka BP $(24,2$ - 21,7 ka cal BP) se van encadenando los principales rasgos tecnoeconómicos solutrenses: tratamiento térmico del sílex, retoque por presión, bifacialidad y pedunculación (Rasilla 1994; Tiffagom 1998, 2006a). Durante los últimos 25 años se han incrementado los sitios con puntas de aletas y pedúnculo y puntas de escotadura, en contraste con lo sucedido con los conjuntos de puntas de cara plana.

Sólo los datos preliminares para la Boja (SW18E: punta de cara plana) señalan la identificación del Solutrense inferior en ca. 21 ka BP (Zilhão et al. 2010; Lucena et al. 2012), en un umbral cercano a los sitios tratados en el epígrafe anterior y a Les Malladetes y Parpalló, yacimientos que han sido el origen de los ciclos historiográficos descritos al principio de este texto. Pero a continuación se registra un vacío de datas entre 21 - 20 ka $\operatorname{BP}(25,1$ - 23,6 ka cal BP) y sólo en los extremos de este segmento temporal encontramos 3 conjuntos, también con datos desiguales (Tabla 1). Cueva Ambrosio II.1 proporciona la datación más antigua para un conjunto con presencia de puntas de pedúnculo y aletas y escotadura (Ripoll et al. 2006; Múñoz 2000). Mientras que los datos sobre Santa Maira CG II indican que existen conjuntos cercanos a $20 \mathrm{ka}$ BP en los que el utillaje solutrense queda limitado a foliáceos bifaciales, sin piezas pedunculadas ni de escotadura por ahora; quizás sea también el caso de Peña Capón 4 (Fig. 5). Las primeras puntas pedunculadas se identificaron en el Solutrense medio de Parpalló -alguna escotadura también- pero con un número reducido de ejemplares (Pericot 1942; Fullola Pericot 1979) y también en Malladetes Va-V (Fortea y Jordá 1976). Las fechas de ambos yacimientos tienen una SD elevada, pero podrian fechar las primeras hojas de laurel pedunculadas poco después de ¿20 ka BP?

A estas incertidumbres se añade el hecho de que las dataciones radiocarbónicas del Solutrense evolucionado muestran una distribución muy amplia (25,7 - 21,7 ka cal BP), con resultados que llegan a solaparse tanto con las del Protosolutrense y Solutrense inicial, como con las del Badeguliense y Magdaleniense. Una amplitud temporal compatible con la larga secuencia en fases del Solutrense ibérico, derivada en gran medida del modelo de sucesión de las puntas de piedra.

La cronología radiocarbónica indica que entre 19,5 y 19 ka BP (23,5 - 22,5 ka cal BP), arrancan los contextos del Solutrense superior de puntas pedunculadas de retoque por presión y de escotadura de retoque abrupto (Ambrosio, Rambla Perea y Parpalló - Malladetes, aunque sin dataciones validadas). Las pedunculadas desaparecen, no por completo, a partir de 19 ka BP, multiplicándose los proyectiles fabricados mediante retoque abrupto (Ambrosio, Beneito, Cendres, Parpalló y Malladetes), que según la cronología actualmente aceptada podrían prolongarse hasta 16,5 ka BP (Fig. 5).

\subsection{La perduración solutrense}

La idea de una perduración solutrense con respecto a las regiones francesas ha tenido arraigo desde Jordá (1955 y 1958) y quedó reforzada a partir de los resultados proporcionados por las primeras dataciones de contextos solutreogravetienses (Malladetes y Parpalló, a las que se unieron Cova Beneito, Cueva Ambrosio o la Ratlla del Bubo: cf. Tabla 1). La entidad estratigráfica de estos niveles en Parpalló también fue un elemento considerado, al igual que su densidad de materiales. Sin embargo, las fechas solutrenses posteriores a 18,5 - 18 ka BP proceden de contextos con una resolución estratigráfica y tecnotipológica que plantea alguna reserva. A esta situación se añaden los resultados obtenidos recientemente para niveles del Badeguliense - Magdaleniense arcaico y Magdaleniense inferior (Aura et al. 2012; Utrilla y Montes 2007; Utrilla et al. 2012; Villaverde et al. 2012), que son "contemporáneas" de una parte de las dataciones que comentaremos en este epígrafe. Precisamente, llama la atención que 5 de las 8 datas para todo el complejo Solutrense con SD superiores a 350 años radiocarbónicos, corresponden al Solutrense evolucionado y Solutreogravetiense (Tabla 1), concentrando por tanto una parte importante de las dataciones descartadas. Su causa puede deberse a una deficiente selección de la muestra, relacionable con procesos sedimentarios y tafonómicos, o a su contaminación.

La Figura 6 compara las curvas obtenidas mediante los dos procedimientos de datación empleados. La elaborada a partir de los resultados del ${ }^{14} \mathrm{C}$ convencional refleja una gran amplitud (21,5 - 16,5 ka BP; 25,8 - 19,3 ka cal BP), entrecortada por un importante vacío intermedio (25 - 22,6 ka cal BP). Estas fechas han sido obtenidas sobre agregados de carbón o hueso, no sobre muestras únicas identificadas taxonómicamente, y han aportado los resultados más antiguos y también más recientes ( $c f$. Ambrosio II y IV). En otros casos se trata de muestras con una SD al límite del criterio 
fijado (Parpalló), de un hogar (Ratlla del Bubo) y de un tramo afectado por erosiones a techo (NV8/s).

Las dataciones AMS muestran una menor amplitud cronológica que las de ${ }^{14} \mathrm{C}$ convencional (24,2 - 19,3 ka cal BP). La mayor probabilidad de la curva se sitúa entre 19,3 y 18,5 ka BP (23,4 - 22,5 ka cal BP), coincidiendo con el incremento sustancial de las producciones laminares - microlaminares y de las puntas de escotadura y utillaje microlaminar de dorso. Esta tendencia se aprecia sobre todo en los yacimientos de larga secuencia y está acompañada también de alguna punta de cara plana, pedunculada y de algún foliáceo.

Una cuestión más incierta es el final de estas producciones. Las datas de ${ }^{14} \mathrm{C}$ muestran un vacio entre 18,3 y $17,9 \mathrm{ka}$ BP y las de AMS entre 18,3 -17,5 ka BP (22 - 21 ka cal BP), seguido de 5 dataciones AMS que se reparten entre 17,4 y 16,2 ka BP (20,8 y 18,8 ka cal BP) y que una vez valorada la baja resolución de las datas de ${ }^{14} \mathrm{C}$ convencional son las que podrian sustentar la perspectiva de una perduración solutreogravetiense. Cada una de estas daciones merece un breve comentario:

- De La Boja SW18B2 se han publicado datos preliminares y se plantea la existencia de procesos de bioturbación (Zilhão et al. 2010: 146; Lucena et al. 2012). Su adscripción solutreogravetiense se basa, hasta ahora, en su posición litoestratigráfica.

- La data de Cendres XIlbase ya ha sido comentada en el apartado 2.2. Recordar que ocupa el techo de los procesos de bioturbación descritos y que en este nivel se reconocen algunos morfotipos badegulienses (Fig. 4), en un conjunto mayoritario de Magdaleniense inferior (Villaverde et al. 2012).

- De Gorham's Cave III-B existen 2 dataciones separadas por 2 ka BP para la ocupación solutrense (Finlayson et al. 2006; Gútierrez López et al. 2012). Los materiales solutrenses (foliáceo, punta de pedúnculo y de escotadura) pueden corresponder a la fecha más antigua.

- La datación de Cova Beneito II (ext.) también ha sido comentada en el punto 2.2. Este nivel ha sido relacionado con el solutreogravetiense, aunque no ha proporcionado puntas de escotadura ni foliáceos solutrenses. Sólo se mencionan piezas con retoque plano y un elevado índice de útiles del sustrato, más de $45 \%$ si consideramos también los esquirlados (Domenech et al. 2012). Estas coincidencias con el Badeguliense de Parpalló podrian ser una alternativa a considerar.

Por tanto, entre 18,5/18 y 16,2 ka BP (22,5 - 19 ka cal BP) las dataciones y contextos datados plantean más incertidumbres que certezas. Los rasgos solutrenses se limitan a alguna punta de cara plana y puntas de escotadura en el mejor de los casos. El incremento del utillaje doméstico (raspadores, piezas retocadas, raederas, muescas-denticulados o cuñas) y de la industria ósea coincide con las dataciones obtenidas para los contextos badeguliensesmagdalenienses arcaico. No obstante, somos conscientes de que estos contextos también merecerian una valoración crítica similar a la anterior, puesto que se trata de conjuntos reducidos (Maltravieso y en menor medida Gato), de excavaciones antiguas (Parpalló) o que no han podido ser datados (Volcán del Faro).

\section{DISCUSIÓN}

Se ha intentado caracterizar los límites del Solutrense ibérico desde la transformación tecnoeconómica de las industrias líticas, incorporando también datos estratigráficacos y radiocarbónicos. Sobre ambas cuestiones se arrastra un importante sesgo, siempre comentado y nunca solventado, pues la información procede de cuevas-abrigos, desconociendo lo ocurrido en los sitios al aire libre.

Para su límite más antiguo, los datos industriales de Nerja muestran una continuidad entre Gravetiense y Solutrense, mayor que la considerada hasta ahora para el conjunto de la región. Sobre tres componentes se articula buena parte de su dinámica tecnoeconómica:

- Una producción laminar de tradición gravetiense, a partir de núcleos prismáticos de frente estrecho y también planos sobre su cara más ancha.

- El segundo componente es la identificación de soportes de estilo Vale Comprido, aunque en Nerja estos soportes tienen una presencia reducida, reconociéndose tanto en contextos gravetienses como solutrenses. La identificación de núcleos-raspadores en ambos yacimientos también es significativa (Tiffagom et al. 2007).

- El tercero es el facetado solutrense, asociado al tratamiento térmico del sílex y a la elaboración de los foliáceos.

El recorrido de los tres componentes es desigual, pues los dos primeros podrían conformar un "episodio de puntas unifaciales", con un mayor peso de las producciones de tradición gravetiense. El tercero corresponde al facetado solutrense y a los rasgos técnicos que se le vinculan.

Esta denominación podría parecer genérica e incluso contradictoria, al aunar producciones gravetienses, protosolutrenses y solutrenses bajo el paraguas de "puntas unifaciales" (sobre soportes apuntados con preparaciones convergentes y de cara plana). A diferencia de lo planteado para Portugal (Zilhão 1997) o el suroeste francés (Renard 2010), en el sur de lberia no se dispone de elementos para el contraste de esta dinámica evolutiva, pues las estrategias 
de producción gravetienses con bajo componente laminar descritas en Bajondillo (Cortés 2007), también Vale Boi (Marreiros y Bicho 2013), tienen poco que ver con las de Nerja y en ambos sitios queda mejor representado el Solutrense evolucionado que las fases plenas.

Los datos radiocarbónicos disponibles para el Protosolutrense - Solutrense inicial son tan escasos que pueden ser compatibles con cualquier alternativa que se proponga. La datación de NV9 y las características tecnoeconómicas de NV10 parecen próximas a Peña Capón 3, aunque con un menor componente de puntas tipo Vale Comprido. En este sentido, existen tres contextos datados en el arranque del Solutrense ibérico que expresan la fragilidad de nuestro conocimiento sobre este momento:

a) Conjuntos con producciones de componente gravetiense y protosolutrense, sin utillaje de dorso y con puntas de cara plana (NV10 y NV9, posiblemente también Parpalló).

b) Conjuntos con puntas de cara plana (Malladetes VI y ¿La Boja? SW18B2).

c) Conjuntos en lo que está presentes la mayoría de morfotipos de puntas solutrenses (Ambrosio IV: cara plana, hojas de laurel, foliáceos asimétricos, puntas pedunculadas y puntas de escotadura). Esta última situación resulta bastante improbable en el contexto ibérico y cabe pensar que existe un desajuste entre la edad obtenida y los materiales asociados.

Los datos de Nerja y Parpalló muestran la vigencia de producciones de tipo gravetiense durante el episodio de puntas unifaciales, una relación que también se señala en el primer arte solutrense (Villaverde et al. 2009), aunque persiste una de las mayores dudas: el papel de los contextos de puntas de cara plana, pues basculan entre las producciones de tradición gravetiense y el "verdadero" Solutrense. Esta situación coincide con un primer vacío radiocarbónico entre 21 y $20 \mathrm{ka} B P$, que introduce incertidumbres sobre la edad de los primeros conjuntos plenos (¿ca. 20,5 - 20 ka BP, 24,7 - 23,7 ka cal BP?) y sobre su relación con las puntas unifaciales. Esta lectura no constituye la única explicación posible, pero si la más ajustada a la información disponible. En la facies atlántica portuguesa se produce una vacío similar y para el suroeste francés se maneja un marco cronológico muy próximo para la sucesión Solutrense inferior - pleno (Renard 2010).

A este vacio le sigue la curva de probabilidad más alta que coincide con los rasgos del Solutrense evolucionado entre 19,5 y 19 ka BP, mientras que a partir de 19 ka BP se incrementa el utillaje fabricado mediante retoque abrupto (puntas de escotadura y utillaje microlaminar). Esta lectura otorga a las producciones faciales (soportes para foliáceos y puntas pedunculadas) una vigencia corta: ¿20,5 - 19 ka BP?, pues a partir de esta referencia se configuran los procesos descritos por Tiffagom (2006a), abandonando el facetado solutrense y desarrollando producciones obtenidas a partir de la talla laminar y microlaminar clásica sobre núcleos prismáticos que serán dominantes entre 19 y 18,5 ka BP.

Un nuevo vacío radiocarbónico se detecta a partir de 18,3 ka BP, tanto en las datas obtenidas mediante ${ }^{14} \mathrm{C}$ como de AMS. Tras esta interrupción, una lista de 11 dataciones se reparten entre 17,9 y 16,2 ka BP que son las que en gran medida sustentan la perspectiva de una cronología larga, ligada a una perduración del Solutreogravetiense. En la mayoría de estos conjuntos la presencia de puntas de cara plana, hojas de laurel y puntas de pedúnculo y aletas es testimonial, cuando se registra.

Esta perspectiva de la perduración es poco compatible con las fechas obtenidas para los escasos contextos del Badeguliense / Magdaleniense arcaico datados, aunque ya hemos mencionado que los sitios y datas merecen una valoración tan crítica como la expuesta en el punto 3.3. Las 5 dataciones disponibles sitúan esta unidad arqueológica entre 18,6 y 17,7 ka $B P(22,6$ - 21,1 ka cal BP), solapándose completamente con las dataciones del Solutreogravetiense comentadas más arriba (17,9 - 16,2 ka BP) y alcanzando el límite del Magdaleniense inferior (16 - 15,3 ka BP, Tab. 1).

La muestra de Parpalló fue tratada mediante ultrafiltración (Higham et al. 2011), lo que ha podido añadir algún siglo de antiguedad a su resultado en comparación con las restantes. En todo caso, a partir de 18,5 ka BP se empieza a detectar una mutación tecnoeconómica de las industrias líticas que se resume en un descenso de las producciones laminares y en el incremento de los que se ha descrito como caracteres badegulienses. En el punto 2.2 se ha argumentado que estas producciones y algunos de sus morfotipos característicos tienen una distribución mayor que la manejada hasta ahora, pero una datación difícil, pues se encuentran asociados a materiales solutreogravetienses. Pero, persisten 2 elementos importantes de difícil resolución; uno es el solapamiento Solutrense superior - Badeguliense y el otro, un tercer vacío de fechas, entre 21,1 y 19,3 ka BP.

En la Fig. 7 se resumen los dos modelos cronológicos que derivan de esta discusión. A la izquierda se muestra la perspectiva de la perduración (= cronología larga) derivada de los datos radiocarbónicos analizados en el punto 3.3. En la columna de la derecha se establecen dos grandes ciclos: el primero con una definición deficiente ("puntas unifaciales") y otro más compacto, que corresponde al Solutrense. El bloque más reciente de fechas atribuidas al Solutreogravetiense ha sustentado, hasta ahora, la idea de la perduración solutrense, aunque una buena parte plantea las suficientes reservas como para proponer una cronología más corta para el Solutrense ibérico. Sus límites están todavía por definir, debido a los procesos sedimentarios que se han descrito en diferentes secuencias, pero los datos de Nerja y Parpalló han permitido una primera aproximación a sus transformaciones tecnoeconómicas. 


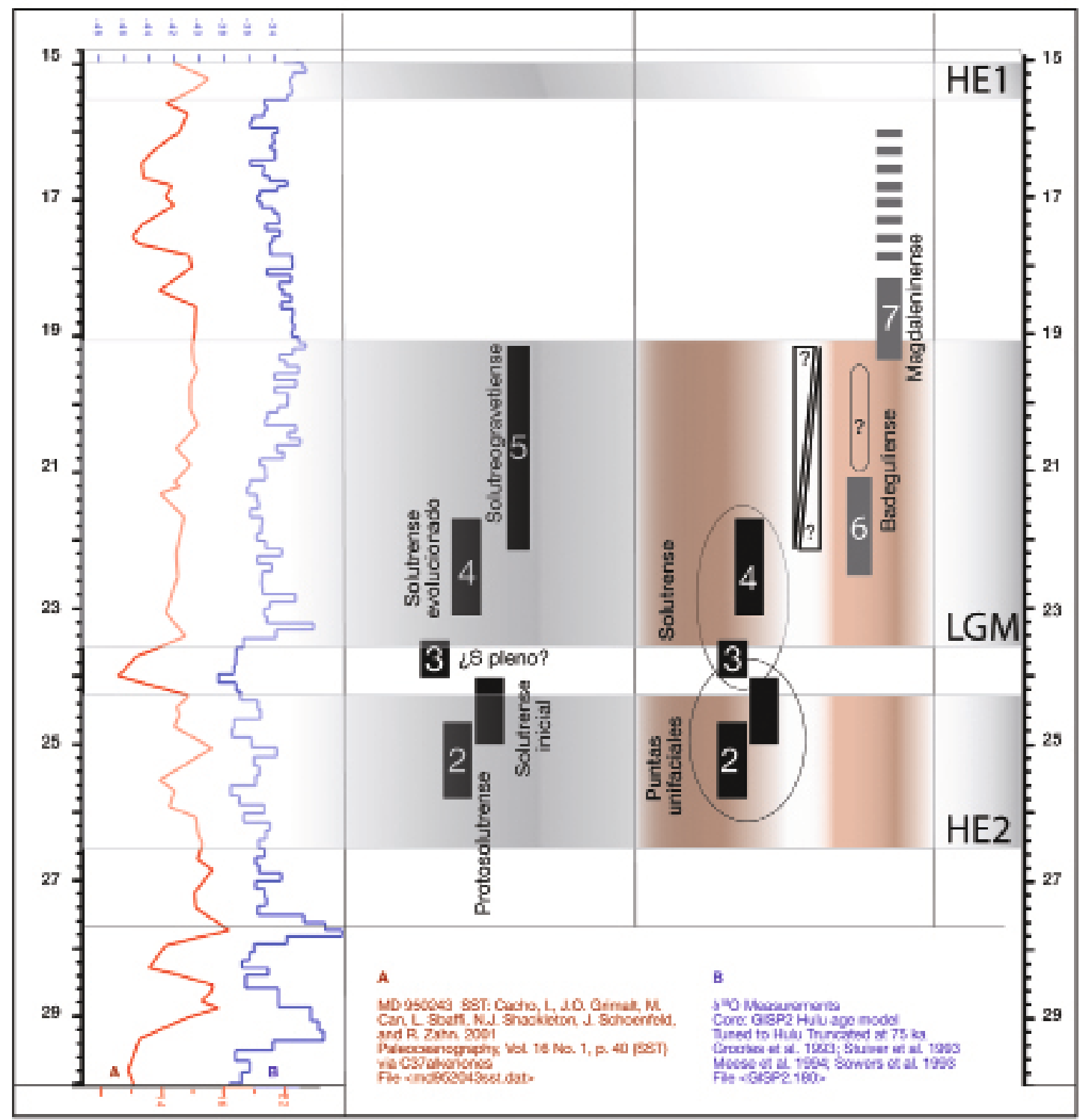

\ FiguRa 7. La secuencia solutrense discutida en el texto. A la derecha la propuesta más aceptada que plantea la perduración solutrense hasta ca. 16,5 ka BP (19 ka cal BP); a la izquierda la alternativa planteada en este texto. Los números del interior de los bloques corresponden a las seis unidades arqueológicas manejadas ( $c f$. punto 3 y Tabla 1). Las referencias a los proxies se encuentran en la leyenda de la Fig. 5.

\section{CONCLUSIONES}

Una buena parte de los temas planteados en los primeros trabajos dedicados al Solutrense ibérico permanecen abiertos. La identificación de las fases sigue estando basada en los cambios en las puntas de piedra y la cuestión de los orígenes no está solventada, pues siguen sobre la mesa las relaciones con el norte de África (Tiffagom 2006b) y con el Protosolutrense (Jordá 1955a; Iturbe et al. 1993; Zilhão y Aubry 1995; Tiffagom et al. 2007; Renard 2010). El impacto de las primeras dataciones radiométricas se mantiene y está asumido que el Solutrense ibérico constituye uno de los nú- cleos regionales más antiguos, pero también uno de los que ofrecen una mayor perduración.

Los datos expuestos indican que las fases críticas del Solutrense ibérico siguen estando en sus límites. En Nerja, el peso de las producciones de origen gravetiense se mantiene durante el Solutrense y se ha propuesto la existencia de una fase de puntas unifaciales desarrollada durante el episodio Heinrich 2, en la que se reconoce la continuidad de las producciones gravetienses, algunos elementos de tipo Vale Comprido y está ausente el retoque por presión (Fig. 7). En otros conjuntos gravetienses también se han descrito hojas apuntadas con retoques someros (Cendres) o la asociación entre soportes 
de estilo Vale Comprido y puntas de cara plana (Nerja y Parpalló), pero habrá que fijar su posición cronoestratigráfica y profundizar en sus relaciones; además, queda por resolver el significado del colapso del utillaje de dorso y una mejor definición de las fases plenas.

En el otro extremo, la transformación de las producciones líticas descrita en Parpalló abre una nueva perspectiva sobre la perduración solutrense pues hasta ahora las dataciones recientes del Solutreogravetiense convertian en invisible el Badeguliense y el arranque del Magdaleniense inferior (Aura 2007; Aura et al. 2012). Entre ambas situaciones se encuentra el "verdadero" Solutrense y los rasgos técnicos que se le vinculan. Su variabilidad configura las fases y facies desarrolladas durante buena parte del LGM, pero si se aceptan los argumentos expuestos, se recortaría sustancialmente el modelo de "cronología larga" solutrense aceptado para la facies ibérica.

Los dos procesos que se sitúan en los límites quedan separados por varios milenios pero son centrales a la hora de analizar las relaciones regionales del Paleolítico occidental durante el Pleniglacial superior. A la definición del Protosolutrense en Portugal (Zilhão et al. 1999) le ha acompañado la descripción de diversos contextos en Francia (Teyssandier et al. 2006; Renard 2010), su referencia en Iberia mediterránea (Tiffagom et al. 2007) y una más completa descripción en el límite meridional de la Meseta (Alcaraz-Castaño et al. 2013). Los datos radiocarbónicos indican una compatibilidad entre estas relaciones regionales, pero sólo eso. En cuanto a la identificación del Badeguliense, la dirección dominante de las relaciones ha sido norte-sur, a pesar de que Parpalló llegó a constituir un yacimiento-tipo en la secuencia Protomagdaleniense planteada por Cheynier (1951). Como hemos señalado, estos contextos badegulienses se encuentran repartidos sólo en el ámbito del antiguo "territorio" solutrense y se sitúan en la segunda mitad del LGM. La contemporaneidad entre los rasgos tecnoeconómicos y su recurrencia se ha valorado como testimonio de una interacción arraigada entre los grupos regionales (Sauvet et al. 2008).

La comparación de la curva de probabilidad acumulada de las dataciones obtenida ahora con la publicada en 2006 muestra que los límites del Solutrense siguen concentrando una buena parte de los interrogantes, aunque se han producido algunas novedades. No se conocen conjuntos datados entre 28-26 ka calBP, pero se dispone de nuevas referencias para el episodio de puntas unifaciales y también se ha producido un incremento sustancial entre 22-19 ka calBP, aunque los conjuntos muestran atribuciones y características tecnoeconómicas diversas (Solutreogravetiense, Badeguliense / Magdaleniense arcaico). Sin embargo, persisten dos vacíos de desigual amplitud que afectan, una vez más, a sus límites. El primero (21 - $20 \mathrm{ka} \mathrm{BP}$ ), incide sobre las relaciones entre los contextos de puntas unifaciales y las industrias solutrenses, en el sentido restrictivo adoptado en este texto. El segundo (18,3 - 17,5 ka BP, según las datas AMS) afecta a los conjuntos solutrenses, pero no a los badegulienses pues es en este rango donde se sitúan las dataciones de estos contextos. Desconocemos si estos apagones son el reflejo de simples procesos sedimentarios, pero es interesante destacar que el primero coincide con el interludio entre $\mathrm{H} 2$ y LGM, por lo que podrian buscarse causalidades ocupacionales y demográficas que exceden los objetivos marcados para este texto; mientras que el segundo pudo combinar procesos tafonómicos y algún ciclo de inestabilidad en la producción del radiocarbono, pues las fechas quedan muy solapadas, amesetadas.

Los componentes descritos y su recorrido configuran un proceso tecnoeconómico muy dinámico que requiere contraste a nivel regional. La valoración crítica de las dataciones radiocarbónicas configura una alternativa que no excluye otras posibilidades de interpretación, pero la planteada incide sobre las relaciones de los grupos regionales en los inicios del Paleolítico superior final. Ambas perspectivas coinciden en lo escrito al principio de este texto: el Solutrense fue un tecnocomplejo breve, pero con una gran visibilidad.

\section{AGRADECIMIENTOS}

Una parte sustancial de los datos utilizados para este trabajo fueron obtenidos dentro del Proyecto HAR200803005 del Ministerio de Ciencia e Innovación: La Transición Solutrense - Badeguliense - Magdaleniense en la Península ibérica (19000 - 15000 años BP) (SOBAMA). •

\section{BIBLIOGRAFÍA}

AlmeIDA, A. 2000: The Terminal Gravettian of Portuguese Estremadura: Technological Variability of the Lithic Industries. PhD Dissertation. Southern Methodist University. Dallas.

Álvarez-Castaño, M., Alcolea, J., De Balbin Behrmann, R., García Valero, M. A., Yravedra Sainz De Los Terreros, J. y Baena Preysler, J. 2013: "Los origenes del Solutrense y la ocupación pleniglaciar del interior de la Península Ibérica: implicaciones del nivel 3 de Peña Capón (valle del Sorbe, Guadalajara)". Trabajos de Prehistoria 70 (1): 28-53.
Aparicio, J. 2003: El paleomesolítico valenciano: Cova del Volcán del Faro: memoria de las excavaciones e inventario del material. Real Academia de Cultura Valenciana, Sección de Prehistoria y Arqueología. Valencia.

Aubry, T., Almeida, M., Chehmana, L., Thiennet, H. y Walter, B. 2007: "De la fin du Solutréen au Magdalénien moyen dans les vallées de la Claise et de la Creuse". Bulletin de la Société préhistorique française 104: 699-714.

Aubry, T., Walter, B., AlmeidA, M., LIARD, M. y NeVES, M. J. 2004: "Approche fonctionnelle des sites dits d'atelier: I'exemple des occupations solutréennes et badegouliennes de Maîtreaux (Indre-et-Loire, 
France)". En: Bodu, P., Constantin, C. (Eds.), Approches fonctionneIles en Préhistoire, Actes du XXV congrès préhistorique de France, Nanterre 24-26 November 2000. Société préhistorique française. Paris: $249-263$.

Aubry, T., Almeida, M., Chehmana, L., Thiennet, H. y Walter, B. 2007: "De la fin du Solutréen au Magdalénien moyen dans les vallées de la Claise et de la Creuse". Bulletin de la Société préhistorique française 104: 699-714.

Aura Tortosa, J. E. 1988: La Cova del Parpalló y el Magdaleniense de facies ibérica o mediterráneo. Propuesta de sistematización de su cultura material: industria lítica y ósea. Universitat de València. València.

- 1995: El Magdaleniense Mediterráneo: la Cova del Parpalló (Gandía, Valencia). Trabajos Varios del SIP 91. Museu de Prehistòria. Valencia.

- 2007: "Badegouliens et Magdaléniens du versant méditerranéen espagnol". Bulletin de la Société préhistorique française 104: 809-824.

Aura Tortosa, J. E., Jordá Pardo, J. F. y ForteA, F. J. 2006: "La Cueva de Nerja (Málaga, España) y los inicios del Solutrense en Andalucía". Zephyrvs LIX: 73-94.

Aura, J. E., Jordá Pardo, J. F., Pérez Ripoll, M., Badal, E., Morales, J. V., AvezUelA, B., TIFAgOM, M., JARdóN, P. 2010: "Treinta años de investigación sobre el Paleolítico superior de Andalucia: la Cueva de Nerja (Málaga, España)". En X. Mangado (ed.): El Paleolítico superior peninsular. Novedades del siglo XXI. Homenaje al Profesor Javier Fortea. Monografies 8. SERP. Barcelona: 149-172.

Aura, J. E., Jordá Pardo, J. F., Avezuela, B., Pérez Ripoll, M., Tiffagom, M. y Morales Pérez, J. V. 2010B: "La Cueva de Nerja (Málaga) y el Gravetiense en Andalucia". Cuaternario y Arqueología. Homenaje a F. Giles Pacheco: 125-132.

Aura, J. E., Tiffagom, M., Jordá Pardo, J. F., Duarte, E., Fernández De la Vega, J., Santamaría, D., De la Rasilla, M., Vadillo, M. y Pérez, M. 2012: "The Solutrean - Magdalenian Transition: a view from the southwest". Quaternary International 272-273: 75-87.

Aura, J. E., Jordá Pardo, J. F., Pérez Ripoll, M., Badal García, E., Avezuela, B., Morales Pérez, J. V., Tiffagom, M., Wood, R. y Marlasca, R. 2013: "El corredor costero meridional: los cazadores gravetienses de la Cueva de Nerja (Málaga, España)". En C. de las Heras, J. Antonio Lasheras, Á. Arrizabalaga y M. de la Rasilla (coords.): Pensando el Gravetiense: nuevos datos para la Región Cantábrica en su contexto peninsular y Pirenaico. Monografias del Museo Nacional y Centro de Investigación de Altamira 23. Ministerio de Educación, Cultura y Deporte: 104-113.

BankS, W. E., Zillião, J., D'ERRICO, F., KageYAma, M., Sima, A. y RonChitelli, A. 2009: "Investigating links between ecology and bifacial tool types in Western Europe during the Last Glacial Maximum". Journal of Archaeological Science 36: 2853-2867.

Banks, W. E., Aubry, Th, D'errico, F., Zillão, J., Lira-Noriega, A. y Townsed PETERSON, A. 2011: "Eco-cultural niches of the Badegoulian: Unraveling links between cultural adaptation and ecology during the Last Glacial Maximum in France. Journal of Anthropological Archaeology 30: 359-374.

Blasco, M. F. y RodAnÉs, J. M. en prensa: "Las fases de ocupación de la Cueva del Gato -2 (Épila, Zaragoza)". Salduie, 9.

Bodu, P. 2005. "Le gisement de Lailly (Yonne) une chaîne opératoire inedited au Paléolithique supérieur? ou un procédé de fabricaion d'éclats-supports pour nucleus à lamelles (grattoirs carénés) au sud du Bassin parisien". Productions lamellaires attribuées $\dot{a}$ I'Aurignacien: Chaînes opératoires et perspectives technoculturelles. XIVe congres de I'UISPP, Liège 2-8 septembre 2001, Luxembourg. Archéologiques 1: 297-310.

Bodu, P., Chehmana, L., Cretin, C., Ducasse, S. y Langlais, M. (orgs.) 2007a: Le dernier Maximum glaciaire et après... en France et en Espagne, Synthèses régionales et reflexions autour de la diversité des cultures materielles de 19000 à 14000 BP. Actes de la Table Ronde Séance de la Société Préhistorique Française. Maison de la RechercheUniversité de Toulouse-le-Mirail (9-10-2006). Bulletin de la Société préhistorique française 104 (4): 655-824.
Bofinger, E. y Davidson, I. 1977. "Radiocarbon Age and Depth: A statistical treatament of two secuences of dates from Spain". Journal of Archaeological Science 4: 231-243.

BosseLIN, B. y DJINDJIAN, F. 1999 : "Une révision de la séquence de la Riera (Asturies) et la question du Badegoulien Cantabrique". Bulletin de la Société préhistorique française 96 (2) : 153-173.

Bracco, J. P., Morala, A., Cazals, N., Cretin, C., Ferullo, O., Faourloubey, CH. y LENOIR, M. 2003: "Peut-on parler de débitage discoïde au Magdalénien Ansien /Badegoulien?". En M. Peresani (ed.): Discoid Lithic Technology. Advances and implications. BAR International Series 1120. 0xford: 83-115.

BrEUIL, H. 1912: "Les subdivisions du Paléolithique supérieur et leur signification". Congrès International d'Anthropologie et d'Archéologie Préhistoriques. Compte Rendu de la XIVe session, Genève, (1937, 2nd Ed).

Cacho, I., Grimalt, J. O., Canals, M., Sbaffi, L., Shackleton, N. J., Schönfeld, J. y ZAHN, R. 2001: "Variability of the western Mediterranean Sea surface temperature during the last 25.000 years and its connection with the Northern Hemisphere climate changes". Paleoceanography 16 (1): 40-52.

Cacho, C., Martos, J. A., Jordá Pardo, J. F., Yravedra, J., Avezuela, B., ValDiviA, J. y Martín, I. 2010: "El Paleolítico superior en el interior de la Peninsula Ibérica. Revisión critica y perspectivas de futuro". En $X$. Mangado (ed.): El Paleolítico superior peninsular. Novedades del siglo XXI. Homenaje al Profesor Javier Fortea. Monografies 8. SERP. Barcelona: 115-136.

Canals, A., Rodriguez, A., Peña, L., Mancha, E., García-Díez, M., Bañuls, S., Euba, I., López, J. M., Barrero, N., Bermejo, I., Garcia, F. J., Mejias, D., Modesto, M., Morcillo, A., Aranda, V. y Carbonell, E. 2010: "Nuevas aportaciones al Paleolítico superior del suroeste peninsular: la cueva de Maltravieso, más allá del santuario extremeño de las manos". En $X$. Mangado (ed.): El Paleolítico superior peninsular. Novedades del siglo XXI. Homenaje al Profesor Javier Fortea. Monografies 8. SERP. Barcelona: 199-218.

Cava, A. 1997: "La industria lítica tallada de la Cueva de Nerja". En M. Pellicer y P. Acosta (coords.): El Neolítico y Calcolítico de la Cueva de Nerja. Trabajos sobre la Cueva de Nerja 6. Patronato de la Cueva de Nerja. Málaga: 223-348.

CHEYNIER, A. 1951: "Les industries protomagdaléniennes". Bulletin de la Société préhistorique française 48: 190-192.

Corchón, M. S. 1981: La cueva de Las Caldas, San Juan de Priorio (Oviedo). Excavaciones Arqueológicas en España 15. Ministerio de Cultura. Madrid.

Cortés Sánchez, M. (ed.) 2007: Cueva de Bajondillo (Torremolinos). Secuencia cronocultural y paleoambiental del Cuaternario reciente en la Bahía de Málaga. Servicio de Publicaciones. Centro de Publicaciones de la Diputación de Málaga, Málaga.

CREtin, C. 2007: "Arrêt sur le Badegoulien: Historique, état de la question et perspectives". En J. Évin (ed.): Un Siècle de Construction du discours scientifique en Préhistoire, Des Idées d'hier 1. Actes $d u$ 26eme Congrès Préhistorique de France, Avignon 2004. Société préhistorique française. Paris: $367-378$.

Cretin, C., Ferullo, O., Fourloubey, C., Lenoir, M. y Morala, A. 2007: "Le Badegoulien du nord de l'Aquitaine: de noveaux moyens de lectura". Bulletin de la Société préhistorique Française 104 (4): 715-734.

DavidSON, I. 1974: "Radiocarbon dates for Spanish Solutrean". Antiquity 48: 63-65.

- 1976a: "Les Mallaetes and Mondúver: the economy of a human group in prehistoric Spain". Problems in economic and social Archaeology. Ed. Duckworth. Londres.

Domenech Faus, E., Bergadè Zapata, M. M. y Roca De Togores Múñoz, C. 2012: "Nuevas aportaciones al Paleolitico superior medio de la Cova Beneito (Muro, Alacant)". Recerques del Museu d'Alcoi 21: 7-18.

DuCASSE, S. 2010: La "parenthèse" badegoulienne: Fondements et statut d'une discordance industrielle au travers de l'analyse techno-économique de plusieurs ensembles lithiques méridionaux du Dernier 
Maximum Glaciaire. Unpublished Ph.D. Dissertation. University of Toulouse. Toulouse.

Ducasse, S. y Langlals, M. 2007: "Entre Badegoulien et Magdalénien, nos coeurs balancent... Approche critique des industries lithiques du Sud de la France et du Nord-Est espagnol entre 19000 et 16500 BP". Bulletin de la Société préhistorique française 104 (4) : 771-785.

Finlayson, C., Giles Pacheco, F., Rodriguez-Vidal, J., Fa, D., GutiérRez López, J. M., Santiago Pérez, A., Finlayson, G., Allué, E., Baena Preysler, J., CÁCeres, I.,Carrión, J., Fernández Jalvo, Y., Gleed-OWen, C., Jiménez Espejo, F., López, P., López Sáez, J.-A., Riquelme Cantal, J. A., Sánchez Marco, A., Glles Guzman, F., Brown, K., Fuentes, N., Valarino, C., VIllalpando, A., Stringer, C. B., Martinez Ruiz, F. y Sakamoto, T. 2006: "Last survival of Neanderthals at the southernmost extreme of Europe". Nature 443: 850-853.

FoRTEA PéreZ, F. J. 1973: Los complejos microlaminares y geométricos del Epipaleolítico mediterráneo español. Seminario de Prehistoria y Arqueologia, Memoria 4,. Universidad de Salamanca. Salamanca.

- 1978: "Arte Paleolítico del Mediterráneo español". Trabajos de Prehistoria 35: 99-149.

- 2005: "La plus ancienne production artistique du Paléolithique iberique". Simposio Pitture Paleolitiche nelle Prealpi venete. Grotta di Fumane e Riparo Dalmieri (Verona 2003). Prehistoria Alpina No speciale: $53-65$.

ForteA, J. y JORDÁ CeRDÁ, F. 1976: La Cueva de les Mallaetes y los problemas del Paleolítico superior del Mediterráneo español. Zephyrvs XXVI-XXVII: 129-166.

Fortea, J., Fullola, J. M., Villaverde, V., Davidson, I., Dupré, M. y Fumanal, M. P. 1983: Schéma paleoclimatique, faunique et chronostratigraphique des industries à bord abattu de la région méditerranéenne espagnole. Rivista di Scienze Preistoriche 38 (1-2): 21-67.

Fullola Pericot, J. M. 1978: "El Solútreo-Gravetiense o Parpallense, industria mediterránea". Zephyrvs XXVIII-XXIX: 113-117.

- 1979. Las industrias líticas del Paleolítico Superior Ibérico. Trabajos Varios del SIP 60. Museu de Prehistòria. València.

Fumanal, M. P. 1986. Sedimentología y Clima en el Pais Valenciano. Las Cuevas habitadas en el Cuaternario reciente. Trabajos Varios del SIP 83. Museu de Prehistòria. Valencia.

Gamble, C., Davies, W., PetTim, P. y Richards, M. 2004: "Climate change and evolving diversity in Europe during the Last glacial". Phil. Trans. Royal Soc. London (B) 359: 243-254.

Gutiérrez López, J. M., Giles Pacheco, F., Giles Guzmán, F. J., Finlayson, C., Bernal, M., Rodriguez Vidal, J., Finlayson, G. y FA, D. A. 2012: "La ocupación solutrense de tramo interno de Gorham's Cave, Gibraltar". En B. Avezuela y J. F. Jordá Pardo (coords.): Congreso Internacional EI Solutrense. Centenario de las excavaciones en la Cueva de Ambrosio, Vélez-Blanco, Almería (España). Madrid: 59-60.

Grootes, P. M., Stuiver, M., White, J. W. C., Johnsen, S., JOUzeL, J. 1993: "Comparison of Oxygen Isotope Records from the GISP2 and GRIP Greenland Ice Core". Nature 366: 552-554.

HIGHAM, T. 2011: "European Middle and Upper Palaeolithic radiocarbon dates are often older than they look: problems with previous dates and some remedies". Antiquity 85 (327): 235-249.

HoYos, M. 1994: "Características sedimentokársticas y paleoclimáticas de los interestadios de Laugerie-Lascaux en la Cornisa Cantábrica". Férvedes 1: 21-37.

Iturbe, G., Fumanal, M. P., Carrión, J. S., Cortell, E., Martinez Valle R., Guillem P. M., Garralda M. D. y Vandermeersch, B. 1993: "Cova Beneito (Muro, Alicante): una perspectiva interdisciplinar". Recerques del Museu d'Alcoi 2: 23-88.

ITURBE, G. y CoRTELL, E. 1987: "Las dataciones de Cova Beneito y su interés para el Paleolítico Mediterráneo". Trabajos de Prehistoria 44: 267-270.

JORDÁ CERDÁ, F. 1954: "Gravetiense y Epigravetiense en la España mediterránea". Publicaciones del Seminario de Arqueología y Numismática Aragonesa 4: 7-30.
- 1955a: El Solutrense en España y sus problemas. Servicio de Investigaciones Arqueológicas. Diputación Provincial de Asturias. Oviedo.

- 1955b: "Sobre la edad solutrense de algunas pinturas de la cueva de La Pileta (Málaga)". Zephyrvs 6: 131-143.

- 1958: Avance al estudio de la Cueva de la Lloseta. Diputación de Oviedo. Oviedo.

JoRdÁ PARDO, J. F. 1992: Neógeno y Cuaternario del extremo oriental de la costa de Málaga. Tesis Doctoral. Departamento de Geología. Universidad de Salamanca. España.

JoRDÁ PARDO, J. F. y AURA, J. E. 2008: "40 fechas para una cueva. Revisión critica de 70 dataciones ${ }^{14} \mathrm{C}$ del Pleistoceno superior y Holoceno de la Cueva de Nerja (Málaga, Andalucía, España)". En Ripoll López, S. (coord.): Homenaje al profesor Ripoll Perelló. Espacio, Tiempo y Forma. Serie I, Nueva época. Prehistoria y Arqueología 1: 239-256.

Lucena, A., Martinez, S., Angeluccl, D., Villaverde, V., Zapata, J. y Zilläo, J. 2012: "La ocupación solutrense del Abrigo de la Boja (Mula, Murcia)". En B. Avezuela y J. F. Jordá Pardo (coords.): Congreso Internacional El Solutrense. Centenario de las excavaciones en la Cueva de Ambrosio, Vélez-Blanco, Almería (España). Madrid: 146-147.

LE BRUN-RICALENS, F. y BROU, L. 2003: "Burins carénés-nucléus à lamelles: identification d'une chaîne opératoire particulière à Temes (Yonne) et implications". Bulletin de la Société préhistorique française 100 (1): 67-83.

MANGADO, X. (ED.) 2010: El Paleolítico superior peninsular. Novedades del siglo XXI. Homenaje al Profesor Javier Fortea. Monografies 8. SERP. Barcelona.

Marreiros, J., Bicho, N. 2013: "Lithic technology variability and human ecodynamics during the Early Gravettian of Southern Iberian Peninsula". Quaternary International doi.org/10.1016/j. quaint.2013.05.008

Meese, D., Alley, R., Gow, T., Grootes, P. M., Mayewski, P., Ram, M., TAylor, K., WAdDINGTON, E. y ZIELINSKI, G. 1994: "Preliminary depth-age scale of the GISP2 ice core". CRREL Special Report 94-1. Cold Regions Research and Engineering Laboratory. Hanover - New Hampshire.

MuÑoz IBÁÑEZ, F. J. 2000: Las puntas ligeras de proyectil del Solutrense Extracantábrico: análisis tecnomorfológicos e implicaciones funcionales. Serie Aula Abierta. UNED. Madrid.

PeÑa Alonso, P. DE LA 2011: Sobre la unidad tecnológica del Gravetiense en la Península ibérica: implicaciones para el conocimiento del Paleolítico superior inicial. Tesis Doctoral. Departamento de Prehistoria. Universidad Complutense. Madrid.

Pericot, L. 1942: La Cova del Parpalló (Gandía,Valencia). C.S.I.C. Instituto Diego Velázquez, Madrid.

Rasilla Vives, M. De La y Llana Rodriguez, C. 1994: "La cronología radiométrica del Solutrense en la Península Ibérica y su Correlación Crono-Climática". Férvedes 1: 57-67.

RASILLA VIVES, M. DE LA 1994: "El Solutrense en la cornisa cantábrica". Férvedes 1: 9-19.

RAsilla VIVES, M. de LA y SANTAMARí, D. 2006: "Tecnicidad y Territorio: las puntas de base cóncava del Solutrense cantábrico". Munibe 57 (2): 149-158.

RAsilla VIVES, M. de LA y Straus, L. G. 2006: "El poblamiento en la región cantábrica en torno al Último Máximo Glacial: Gravetiense y Solutrense". En M. A. Fano (coord.): Las Sociedades del Paleolítico en la Región Cantábrica. KOBIE (serie Anejos n. ${ }^{\circ}$ 8). Bilbao: 209-242.

ReNARD, C. 2010: Les premières expressions du Solutréen dans le SudOuest français. Evolution techno-économique des équipement lithiques au cours du Dernier Maximum Glaciaire. BAR International Series 2070. Oxford.

Ripoll Pereló, E. 1960-61: "Excavaciones en Cueva Ambrosio (VélezBlanco, Almería). Campañas de 1958 y 1960". Ampurias XXII-XXIII: 31-45.

Ripoll López, S. (ED.) 1988: La cueva de Ambrosio (Almería, Spain) y su posición cronoestratigráfica en el Mediterráneo occidental. BAR International Series 462. 0xford. 
Ripoll López, S. y CACHO, C. 1990: "Le Solutréen dans le sud de la Peninsule Ibérique". En J. K. Kozlowski (dir.): Feuilles de pierre. Les industries à pointes foliases du Paléolithique supériur européen. Actes $d u$ Colloque de Cracovie. ERAUL 42: 449-465.

Ripoll López, S., Muñoz Ibáñez, F. J. y Latova Fernández-LunA, J. 2006. "Nuevos datos para el arte rupestre paleolítico de La Cueva de Ambrosio (Vélez Blanco, Almería)". Congreso de arte esquemático en la Península Ibérica. Vélez-Rubio-Vélez-Blanco, (Almería 5-7 Mayo 2004). Almería: 547-562.

Rodrigo Garcia, M. J. 1988: "El Solútreo-gravetiense de la Cova del Parpalló (Gandía): algunas consideraciones sobre el solútreo-gravetiense en la secuencia del Paleolítico superior del área mediterránea peninsular". PLAV-Sagvntvm 21: 9-46.

Schmidt, I., BradtmölleR, M., Kehl, M., Pastoors, A., Tafelmaier, Y., WeninGER, B. y WENIGER, G. - C. 2012: "Rapid climate change and variability of settlement patterns in Iberia during the Late Pleistocene". Quaternary International 274: 179-204.

Sauvet, G., Fortea, J., Fritz, C. y Tosello, G. 2008: Crónica de los intercambios entre los grupos humanos paleolíticos. La contribución del arte para el periodo 20000-12000 años BP. Zephyrvs 61: 33-59.

Sмітн, Рн. 1966. Le Solutréen en France. Delmas. Bordeaux.

Soler, B., BadAl, E., Villaverde, V. y AurA, J. E. 1990: "Notas sobre un hogar Solútreo-gravetiense del Abric de la Ratlla del Bubo (CreviIlent, Alacant)". Archivo de Prehistoria Levantina XX: 79-94.

Soler, B., V., Tiffagom M. y AuRA, J. E. 2013: "La cova del Volcán del Faro (Cullera, Valencia): més preguntes que respostes i primeres dades sobre els elements d'ornament". En A. Sanchis y Josep LI. Pascual (eds.): leres. Jornades de Arqueozoología. Museu de Prehistòria. Valencia.

Straus, L. G. 1975: "¿Solutrense o Magdaleniense inferior cantábrico? Significado de las diferencias". Boletin del Instituto de Estudios Asturianos 86: 781-790.

- 1983: El Solutrense Vasco-Cantábrico: Una Nueva perspectiva. Monografias del Museo Nacional y Centro de Investigación de Altamira 10. Santander.

- 1990: "The original arms race: Iberian perspectives on the Solutrean phenomenon". En J. K. Kozlowski (dir.): Feuilles de pierre. Les industries à pointes foliases du Paléolithique supériur européen. Actes $d u$ Colloque de Cracovie. ERAUL 42: 425-477.

Straus, L. G., Bicho, N. y Winegardner, A. C. 2000. "The Upper Paleolithic settlement of Iberia: first-generation maps". Antiquity 74: 553-566.

TIFFAGOM M. 1998: "Témoignages d'un traitement thermique des feuilles de laurier dans le Solutréen superior de la Cova del Parpalló (Gandia, Espagne)". Paléo 10: 147-162.

- 2006A: De la Pierre à l'Homme. Essai sur une Paéoanthropologie solutréenne. ERAUL, 113.

- 2006B: "El Solutrense de facies ibérica o la cuestión de los contactos mediterráneos (Europa, África) en el Último Máximo Glacial". En JU. L. Sanchidrián, A. M. Márquez y J. M. Fullola (eds.): IV Simposio de Prehistoria Cueva de Nerja. La Cuenca Mediterránea durante el Paleolítico Superior 38000-10000 años. Reunión de la VIII Comisión del Paleolítico Superior U.I.S.P. Fundación Cueva de Nerja. Nerja: 60-77.

Tiffagom, M., Aura, J. E; Villaverde, V. y Fullola, J. M. 2007: "Entre Gravettien et Solutréen en Espagne méditerranéenne: mise en evidence d'una phase intermédiaire à composition mixte?". Colloque international Le Solutréen... 40 ans après de Smith'66 (Preuilly-sur-Claise 2007), Preactas: $18-19$.

Teyssandier, N., Renard, C., Bon, F., Deschamps, M., Gardère, Ph., Phillppe, LafitTe, Ph., Normand; Ch. y Tarriño, A; 2006: "Premières données sur le site de Marseillon (Banos, Landes): un nouveau gisement solutréen de plein air en Chalosse?". Archéologie des Pyrénées Occidentales et des Landes 25: 105- 120.

UtRILLA, P. 1981: El Magdaleniense Inferior y Medio de la Costa Cantábrica. Monografías del Museo Nacional y Centro de Investigación de Altamira 4. Santander.
- 2006: "Evolución histórica de las sociedades cantábricas durante el Tardiglacial: el Magdaleniense inicial, inferior y medio (1650013000 BP)". En M. A. Fano (coord.): Las Sociedades del Paleolítico en la Región Cantábrica. KOBIE (serie Anejos n. ${ }^{\circ}$ 8). Bilbao: 243-274.

UtRILLA, P. y MonteS, L. 2007: "La periode 19000-14000 BP dans le Bassin de l'Ebre". Bulletin de la Société préhistorique française 104: 797-807.

Utrilla, P., Montes, L., Mazo, C., Alday, A., Rodanés, J. M., Blasco, M. F., Domingo, R. y BEA, J. M. 2010: "El Paleolítico superior $r$ la cuenca del Ebro a principios del siglo XXI. Revisión y novedades". En X. Mangado (ed.): El Paleolítico superior peninsular. Novedades del siglo XXI. Homenaje al Profesor Javier Fortea. Monografies 8. SERP. Barcelona: 23-61.

Utrilla, P., Domingo, R., Montes, L., Mazo, C., Rodanés, J. M., Blasco, M. F. y ALDAY, A. 2012: "The Ebro Basin in NE Spain: A Crossroad during the Magdalenian". Quaternary International 272-273: 88-104.

VADILlo CONESA, M. 2012: "Les industries lítiques del Badegulià al Maditerrani peninsular. Estata actual de les investigacions". Archivo de Prehistoria Levantina XXIX: 81-98.

Villaverde, V. 1994: Arte paleolitico de la Cova del Parpalló. Estudio de la colección de las plaquetas y cantos grabados y pintados. Museo de Prehistoria, Valencia.

Villaverde, V. y Peña, J. L. 1981: Piezas con escotadura del Paleolítico Superior valenciano. Trabajos varios del SIP 69. Museu de Prehistòria. València.

VILLAVERDE V. y Fullola, J. M. 1990: Le Solutréen de la zone méditerranéenne espagnole. En J. K. Kozlowski (dir.): Feuilles de pierre. Les industries à pointes foliases du Paléolithique supériur européen. Actes du Colloque de Cracovie. ERAUL 42: 467-480.

Villaverde, V., Aura, J. E. y Barton, C. M. 1998: The Upper Paleolithic in Mediterranean Spain: A Review of Current Evidence. Journal of World Prehistory 12 (2): 121-198.

Villaverde, V., Martinez, R., Badal, E., Guillem, P., García, R. y Menargues, J. 1999: "El Paleolítico superior de la Cova de les Cendres (Teulada, Moraira). Datos proporcionados por el sondeo efectuado en los cuadros A/B 17". Archivo de Prehistoria Levantina XXIII: 6-65.

VILLAVERDE, V. y RoMÁn, D. 2004: "Avance al estudio de los niveles gravetienses de la Cova de les Cendres (Moraira, Alicante). Resultados de la excavación del sondeo (cuadro A/B/C-17) y su valoración en el context del Gravetiense mediterráneo ibérico". Archivo de Prehistoria Levantina XXV: 19-59.

Villaverde, V., CARdona, J. y Martinez, R. 2009: "L'art parietal de la Grotte de les Meravelles. Vers une caractérisation de l'art paléolithique pré-magdalénien du versant méditerranéen de la Péninsule lbérique". L'Anthropologie 113: 762-793.

Villaverde, V., Román, D., Pérez Ripoll, M., Martínez, R., Badal, E., Bergadà, M. M., Guillem, P. M., Pérez, M. y Tormo, C. 2010: "El Paleolítico superior en el Pais Valenciano. Novedades y perspectivas". En X. Mangado (ed.): El Paleolítico superior peninsular. Novedades del siglo XXI. Homenaje al Profesor Javier Fortea. Monografies 8. SERP. Barcelona: 85-113.

Villaverde, V., Román, D., Pérez Ripoll, M., Bergadè, M. M. y Real, C. 2012: "The end of the Upper Magdalenian in the Mediterranean Basin of the Iberian Peninsula". Quaternary International 272-273: 33-41.

WENINGER, B. y JörIS, 0. 2004: "Glacial Radiocarbon Calibration. The CalPal Program". En T. Higham, C. Bronk Ramsey y C. Owen, C. (eds.) Radiocarbon and Archaeology. Fourth International Symposium (Oxford 2002). Oxford University School of Archaeology, Monograph 62: 9-15.

WENINGER, B., JörIS, O. y DANZEGLOCKE, U. (EN LíNEA): Glacial radiocarbon age conversion. Cologne radiocarbon calibration and palaeoclimate research package "CALPAL" User manual. Universität zu Köln, Institut für Ur- und Frühgeschichte. Köln. www.calpal.de

Wang, Y. J., Cheng, H., Edwards, R. L., An, Z. S., Wu, J. Y., Shen, C. C. y Dorale, J. A. 2001: "A High-Resolution Absolute-Dated Late Pleistocene Monsoon Record from Hulu Cave, China". Science 294 (5550): 2345-2348. 
ZııHÃo, J. 1997: O Paleolítico Superior da Estremadura Portuguesa, Ed. Colibri, 2 vols. Lisboa.

ZILHÃO, J. y AUBRY, H. 1995: "La pointe de Vale Comprido et les origines du Solutréen". L'Anthropologie 99: 125-142.

ZILHÃO, J., AUBRY, T. y ALMEIDA, F. 1999: "Un modèle technologique pour le passage du Gravettien au Solutréen dans le sud-ouest de l'Europe". En D. Sacchi (ed.): Les faciès leptolithiques du nord ouest méditerra- néen: milieux naturels et culturels. Actes du XXIVe Congrès Préhistorique de France (Carcassonne 1994). Paris: 165-183.

Zilhão, J., Angeluccl, D., Badal, E., Lucena, A., Martín, I., Martinez, S., VILLAVERDE, V. y ZAPATA, J. 2010: Dos abrigos del Paleolítico superior en Rambla Perea (Mula, Murcia). En X. Mangado (ed.): El Paleolitico superior peninsular. Novedades del siglo XXI. Homenaje al Profesor Javier Fortea. Monografies 8. SERP. Barcelona: 137-148. 
